Apidologie, 1972, 3 (1), 5-34.

\title{
ZUM VORKOMMEN UND ZUR HERKUNFT DER FREIEN AMINOSÄUREN IN HONIG
}

\author{
Sur la présence et l'origine des acides aminés libres dans le miel
}

Karl-Gustav BERGNER und Hansjörg HAHN

Institut für Lebensmittelchemie der Universität Stuttgart

SUMMARY

AMINO ACIDS IN HONEY

1. In all the investigated honeys the following amino acids were determined : alanine, arginine, glutamine/asparagine (determined together), histidine, isoleucine, leucine, lysine phenylalanine, proline, serine, threonine, tyrosine and valine.

Cystine, 4-hydroxyproline, methionine and tryptophan were found only in some honeys (tables C. and D).

2. In honey made from sugar fed directly to bees the absolute content of amino acids varied, but the proportions of different acids were strikingly similar (table $A$ ). This is explained by assuming that the bees add varying amounts of their secretion containing amino acids.

3. Examination of the contents of foragers' honey sacs (table B) showed that amino acids were added already during foraging. Proline is added in an amount by far the largest.

4. Only exceptionally was it possible to characterize honey types according to their content of amino acids; f. i. Salvia honey which contains an unusually large amount of phenylalanine.

5. In other honeys it was attempted to evaluate the proportion of individual amino acids by determining from their proline content the amount of secretion added by bees. This was successful only with Rape honey (fig. 3). In the other honeys, the relative amino acid content was calculated in relation to proline $=1000$. This ' ratio' is shown by graph (fig. $1+2)$.

The great number of variables is pointed out on which the amino acid content of honey especially honeydew honey - depends.

6. As shown by Salvia honey it might be possible to use peptides or proteines for characterizing honeys.

7. The amino acid content of honey samples is not sufficiently affected by high temperatures for it to be used as an indication of heat damage to honey or extremely long during storage (table 4). 


\section{ZUSAMMENFASSUNG}

1. In allen Honigen konnten quantitativ bestimmt werden : Alanin, Arginin, Glutamin/ Asparagin (gemeinsam bestimmt), Histidin, Isoleucin, Leucin, Lysin, Phenylalanin, Prolin, Serin, Threonin, Tyrosin und Valin.

Cystin, 4-Hydroxyprolin, Methionin und Tryptophan waren nur in einem Teil der Honige nachweisbar (Tab. $C$ und $D)$.

2. In Zuckerfütterungshonigen war - bei unterschiedlichen absoluten Aminosäurengehalten - die relative Aminosäurenzusammensetzung auffallend ähnlich (Tab. A)

Dies wird mit einer Zugabe von unterschiedlichen Mengen des aminosäurehaltigen Sekrets der Biene erklärt.

3. Die Untersuchung des Honigblaseninhalts von Sammelbienen (Tab. B) zeigte, daß bereits bei der Sammeltätigkeit eine Aminosäuren-Zugabe erfolgt. In weitaus größter Menge wird Prolin zugegeben.

4. Eine Charakterisierung von Honigsorten durch den Aminosäurengehalt war nur in Sonderfällen möglich, z.B. bei Salbeihonig, der ausserordentlich grosse Mengen Phenylalanin enthält.

5. Bei anderen Honigen wurde versucht, aus dem Prolingehalt des Honigs die von den Bienen zugegebene Sekretmenge und damit den von den Bienen stammenden Anteil jeder einzelnen Áminosäure zu errechnen. Dies führte nur bei Rapshonig zu einem Ergebnis (Abb. 3). Für die übrigen Honige wurde der relative Gehalt jeder Aminosäure, bezogen auf Prolin $=1000$, berechnet. Diese 'Verhältniszahl' wurde graphisch dargestellt (Abb. 1 und 2). Auf die grosse Zahl Variabler, die den Aminosäurengehalt eines Honigs - insbesondere eines Honigtauhonigs - bestimmen, wird hingewiesen.

6. Am Beispiel eines Salbeihonigs wird gezeigt, daß möglicherweise Peptide bzw. Proteine zur Sortencharakterisierung von Honigen herangezogen werden können.

7. Die Veränderungen im Aminosäurengehalt von Honigproben, die bei erhöhter Temperatur gelagert worden waren, sind nicht so groß, daß sich dadurch eine Wärmeschädigung oder eine Überlagerung von Honig nachweisen liesse (Tab. 4).

\section{I. - EINFÜHRUNG}

Der Gehalt an freien Aminosäuren wird zur Beurteilung von Herkunft, Herstellungsweise, Lagerung und Verderb der verschiedenartigsten Lebensmittel herangezogen. Auch für die Beurteilung von Honigen könnten die freien Aminosäuren Bedeutung haben; die Ergebnisse der bisherigen Untersuchungen reichen dazu jedoch noch nicht aus. Eine Übersicht iiber die qualitativen oder quantitativen Befunde der wichtigsten Arbeiten geben die Tabellen 1 und 2. Die unterschiedlichen Befunde der einzelnen Autoren lassen sich wohl nicht allein auf Unterschiede in den untersuchten Honigen, sondern auch auf die verschiedenartigen Methoden zur Aufarbeitung, Trennung und Bestimmung der Aminosäuren und die dadurch bedingten unterschiedlichen Nachweisgrenzen zurückführen.

TABLEAU I.

$+:$ in jedem der untersuchten Honige nachgewiesen $=$ mis en évidence dans chacun des miels examinés

$(+)$ : nur in einem Teil der untersuchten Honige nachgewiesen $=$ mis en évidence seulement dans une partie des miels examinés

1) Leucin und Isoleucin nicht getrennt = Leucine et isoleucine non séparées

2) Phenylalanin und Tryptophan nicht getrennt $=$ Phénylalanine et Tryptophane non séparés

AAT $=$ Anionenaustausch $=$ échange d'anions

DC = Dünnschicht-Chromatographie $=$ chromatographie sur couche mince

DNP = Dinitrophenyl = Dinitrophényl

$\mathbf{E P h}=$ Elektrophorese $=$ Électrophorèse

Extr. = Extraktion mit organ. Lösungsmitteln = Extraction par solvants organiques

$\mathrm{JC}=$ Ionenaustausch-Chromatographie = Chromatographie échangeuse d'ions

KAT $=$ Kationenaustausch $=$ échange de cations

$\mathbf{P C}=$ Papier-Chromatographie = chromatographie sur papier

Nota : L'abréviation bzw. signifie : respectivement. 


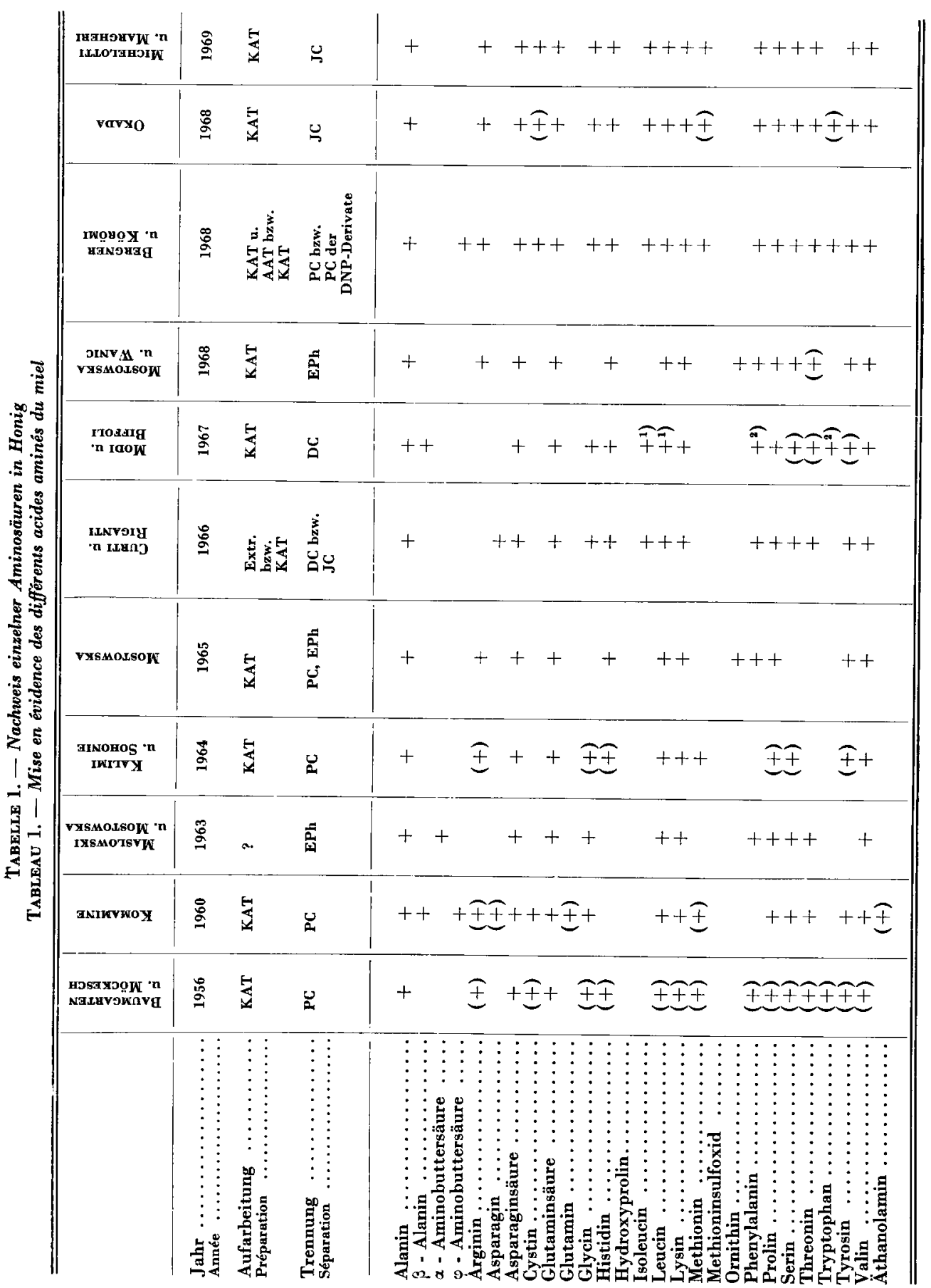


Im einzelnen ist zu bemerken :

Auf den hohen Prolingehalt von Honig (45 bis $80 \%$ der Summe der freien Aminosäuren) wies zuerst Komamine (1960) hin. Mostowska (1965) verglich die Aminosäuren-Gehalte von Nektaren und ( Einartenhonigen 》 (Honigen aus dem Nektar nur einer Pflanzenart) und fand bei den Honigen geringere Schwankungen im Aminosäurengehalt als bei den entsprechenden Nektaren.

Tabelle 2. - Gehalt von Honigen an freien Aminosäuren

Tableau 2. - Teneur en acides aminés des miels

\begin{tabular}{|c|c|c|}
\hline $\begin{array}{l}\text { Autoren } \\
\text { Auteurs }\end{array}$ & $\begin{array}{l}\text { Jahr } \\
\text { Année }\end{array}$ & $\begin{array}{c}\text { n Mol/g Honig } \\
\text { n Mol/g de miel }\end{array}$ \\
\hline TiLLmans und KIEsgen $\ldots \ldots \ldots \ldots \ldots \ldots \ldots \ldots \ldots$ & 1927 & $\begin{array}{l}4500 \text { bis } 17000 \\
\text { jusque }\end{array}$ \\
\hline GotrtFried $\ldots \ldots \ldots \ldots \ldots \ldots \ldots$ & 1929 & 3000 bis 20000 \\
\hline 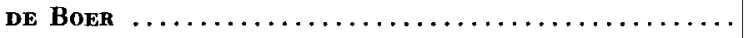 & 1947 & 1750 bis 17500 \\
\hline 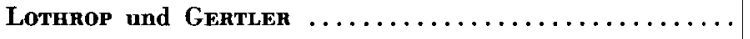 & 1933 & 1400 bis 3600 \\
\hline SchUETTE und BaLDwIN $\ldots \ldots \ldots \ldots \ldots \ldots \ldots \ldots \ldots \ldots \ldots \ldots \ldots \ldots \ldots$ & 1944 & 570 bis 27000 \\
\hline Curti und Riganti $\ldots \ldots \ldots \ldots \ldots \ldots \ldots \ldots \ldots \ldots$ & 1966 & 3000 bis 14000 \\
\hline Michelotti und Margheri $\ldots \ldots \ldots \ldots \ldots \ldots \ldots \ldots$ & 1969 & 2400 bis 4900 \\
\hline $\begin{array}{l}\text { BERGNER und Körömi } \ldots \ldots \ldots \ldots \ldots \ldots \ldots \ldots \ldots \ldots \ldots \ldots \\
\text { zum Vergleich : } \\
\text { à titre de comparaison : }\end{array}$ & 1968 & 2300 bis 3100 \\
\hline $\begin{array}{l}\text { eigene Untersuchungen } \ldots \ldots \ldots \ldots \ldots \ldots \ldots \ldots \ldots \ldots \ldots \ldots \\
\text { recherches personnelles } \ldots \ldots \ldots \ldots \ldots \ldots \ldots \ldots \ldots \ldots \ldots\end{array}$ & 1970 & 2000 bis 17000 \\
\hline
\end{tabular}

Um den Vergleich zu erleichtern, sind die Werte auf $n \mathrm{Mol} / \mathrm{g}$ umgerechnet.

Pour faciliter la comparaison les valeurs sont transformées en $\mathrm{nMol} / \mathrm{g}$.

Einen Zusammenhang zwischen dem Aminosäuren-Gehalt und dem botanischen Ursprung der Proben stellten bereits Lothrop und Gertler (1933), de Barr (1947) und auch Curti und Riganti (1966) fest. Dagegen nahmen Baumgarten und Möckesch (1965) eine Herkunft der freien Aminosäuren des Honigs aus den Drüsensekreten der Biene an. Auf einen von der Biene stammenden Anteil wiesen BERGNER und KöröMI (1968) nach Untersuchung von Zuckerfütterungshonig hin.

Ziel der vorliegenden Arbeit war, zunächst eine möglichst große Zahl der freien Aminosäuren in Honigen quantitativ zu bestimmen und die natürlichen Schwankungen ihrer Mengen zu erfassen. Ferner sollte versucht werden, den von der Biene stammenden Anteil der freien Aminosäuren des Honigs zu ermitteln, um feststellen zu können, ob aus dem Aminosäuren-Gehalt eines Honigs Rückschlüsse auf die von der Biene gesammelten Rohstoffe (die Tracht) möglich sind : 
1. zur Charakterisierung einzelner Honigsorten (neben Pollenanalyse und organoleptischer Prüfung),

2. zum Nachweis einer Verfälschung von Honig durch Zuckerfütterung während der Trachtzeit.

Nebenher sollte geprüft werden, ob aus dem Aminosäurengehalt eine Wärmeschädigung oder eine Überlagerung eines Honigs erkannt werden kann.

\section{II. - METHODIK}

Über die Ausarbeitung einer Methode zur Isolierung der freien Aminosäuren aus Honig unter Abtrennung von Kohlenhydraten, Peptiden und Proteinen mittels einer Kupfer-Chelatharz-Säule, sowie zur Bestimmung der Aminosäuren mittels der automatisierten Ionenaustausch-Chromatographie nach Spackman, Stein und Moore wurde gesondert berichtet (Hahn 1970; BERgNer und HahN 1972).

\section{1. - Gewinnung des Untersuchungsmaterials}

\section{Zuckerfütterungshonige}

Für die Zuckerfütterungshonige A und B wurde jeweils ein kleines Volk der Krainer Biene (Apis mellifica carnica) auf gut geschleuderte, pollenfreie Waben gesetzt. Die weitere Behandlung erfolgte untersehiedlich :

Zuckerfütterungshonige $A$ : Haltung der Bienen in einem Bienenflugraum (ca. $3 \times 6 \mathrm{~m}$ ) bei 23 bis $26^{\circ} \mathrm{C}$ und etwa $40 \%$ rel. Feuchtigkeit. Künstliche Beleuchtung mit Leuchtstoffröhren hinter Mattglas; gleiche Tages- und Nachtlängen mit jeweils 30 min “ Dämmerung » (stufenweises Ein- bzw. Aussehalten der Beleuchtung). Fütterung der Bienen im Stock und ca. 4 m vor dem Flugloch mit Zuckerlösung $1: 2$. Nach einigen Tagen kehrten die meisten der ausgeflogenen Bienen gegen Ende der Lichtperiode in den Stock zurück. Nur ein geringer Anteil der zu Anfang von der Königin abgelegten Eier entwickelte sich zu gedeckelter Brut.

Zuckerfütterungshonige $B$ : Haltung der Bienen im Freien mit einer verdrahteten Flugveranda $(30 \times 30 \times 25 \mathrm{~cm})$ vor dem Flugloch. Fütterung mit Zuckerlösung $1: 2$ innerhalb des Stocks und in der Flugveranda. Es entwickelte sich keine gedeckelte Brut.

Die Zuckerfütterungshonige $A_{1}, A_{2}$ und $A_{7}$ wurden durch Schleudern, alle übrigen durch Aussaugen der Zellen mit einer Kapillare (Wasserstrahlpumpe) gewonnen.

\section{Honigblaseninhalt.}

Etwa 40 vor dem Flugloch abgefangene Flugbienen (Apis mellifica carnica) wurden in einem kleinen Käfig etwa $1 \mathrm{~h}$ lang ausgehungert und dann mit ca. $80 \%$ iger Saccharoselösung gefüttert. Die Bienen wurden mit $\mathrm{CO}_{2}$ kurz betäubt und dann durch leichten Druck auf den Hinterleib zur Abgabe des Honigblaseninhalts veranlaßt (Honigblacerinha't I). Danach wurden dieselben Bienen noch einmal gefüttert und auf gleiche Weise Honigblaseninhalt II gewonnen.

\section{2. - Nachweis von Methioninsulfoxid in Honig}

Bei der Ionenaustausch-Chromatographie der aus Honig isolierten Aminosäuren wurden zur Retentionszeit des Methioninsulfoxids zwei Substanzen 
gemeinsam eluiert (siehe 3.1). Zur Prüfung, ob es sich bei einer dieser Substanzen um Methioninsulfoxid handelt, wurde die Perameisensäure-Oxidation verwendet, mit der Methionin über Methioninsulfoxid in Methioninsulfon übergeführt wird (BLACKBURN 1968). Bei der Ionenaustausch-Chromatographie wird Methioninsulfon von Methioninsulfoxid getrennt, es wird jedoch zusammen mit Serin eluiert.

Der Aminosäuren-Gehalt einer aus Honig gewonnenen Analysenlösung (vergleiche HahN, 1970; Bergner und HahN, 1972) wurde vor und nach Perameisensäure-Oxidation (Reaktionszeit $4 \mathrm{~h}$ bei $0^{\circ} \mathrm{C}$ ) bestimmt. In der oxidierten Probe war der gemeinsame Peak der beiden unbekannten Substanzen um eine $23 \mathrm{nMol}$ Methioninsulfoxid/g Honig entsprechende Fläche kleiner; die Fläche des gemeinsamen Peaks von Serin + Methioninsulfon hatte $26 \mathrm{nMol}$ Methioninsulfon/g Honig entsprechend - zugenommen. Die Vollständigkeit der Perameisensäure-Oxidation wurde durch einen zweiten Ansatz mit verlängerter Reaktionszeit $(14 \mathrm{~h})$ überprüft.

Die erhaltenen Werte stimmten im untersuchten Honig recht gut überein.

\section{III. - ERGEBNISSE}

\section{1. - Aminosäuren}

In allen untersuchten Honigen konnten Alanin, Arginin, Glutamin/ Asparagin, Histidin, Isoleucin, Leucin, Lysin, Phenylalanin, Prolin, Serin, Threonin, Tyrosin und Valin nachgewiesen werden. Nicht erfassbar waren in manchen Honigen Cystin, 4-Hydroxyprolin, Methionin und Tryptophan (Erfassungsgrenze ca. $1 \mathrm{nMol} / \mathrm{g}$ ). Eine weitere Gruppe von Aminosäuren (B-Alanin, $\gamma$-Aminobuttersäure, Asparaginsäure, Glutaminsäure, Glycin und Ornithin) ließ sich nicht in allen Honigen nachweisen, z.B. weil bei der erforderlichen Aufarbeitung zu große Verluste auftraten, oder weil die Auftrennung nur ungenügend erfolgte (siehe BERGNER und HAHN 1972).

Freies 4-Hydroxyprolin, das bisher in Honig noch nicht beobachtet worden war, wurde durch das bei $440 \mathrm{~nm}$ liegende Absorptionsmaximum der mit Ninhydrin gebildeten Färbung erkannt :

Absorptionsmaxima

Iminosäuren

4-Hydroxyprolin

Prolin

Aminosäuren

$\begin{array}{cr}\text { Ninhydrin-Färbung } & \text { Dinitrophenyl-D } \\ & \\ 440 \mathrm{~nm} & 380 \mathrm{~nm} \\ 440 \mathrm{~nm} & 384 \mathrm{~nm} \\ 570 \mathrm{~nm} & 360 \mathrm{~nm}\end{array}$

Zur Bestätigung wurden die Dinitrophenyl-Derivate der aus Honig isolierten Aminosäuren dargestellt, papierchromatographisch getrennt 
(BERgner und Körömi 1968) und ihre Absorptionsmaxima bestimmt. Ủber das Vorkommen von Hydroxyprolin in Pollen - der Eiweißquelle der Biene berichteten Auclair und Jamieson (1948) und Virtanen und Kari (1955).

Cystein wurde bisher nicht nachgewiesen; es ist im oxydierenden Milieu des Honigs auch nicht zu erwarten. Nach White und Schepartz (1963) enthält Honig geringe Mengen $W$ asserstoffperoxid, entstanden bei der enzymkatalysierten Oxydation von Glucose. Cysteinsäure, das Oxydationsprodukt von Cystein bzw. Cystin, konnte allerdings auch nicht nachgewiesen werden.

Die Anwesenheit von Methioninsulfoxid konnte in allen untersuchten Honigen wahrscheinlich gemacht werden.

Methioninsulfoxid wird bei der Ionenaustausch-Chromatographie der Aminosäuren unmittelbar vor Hydroxyprolin eluiert. Die Chromatogramme aller Honige zeigten an dieser Stelle einen Peak. Seine häufig asymmetrische Form - in einigen Fällen auch eine Schulter deuteten darauf hin, daß zu dieser Retentionszeit zwei Substanzen gemeinsam eluiert wurden. Durch Aminosäurebestimmung vor und nach Perameisensäureoxydation der aus einem Honig isolierten Aminosäuren, wobei Methioninsulfoxid zu Methioninsulfon oxydiert wird, konnte Methioninsulfoxid indirekt in einer Menge von ca. $25 \mathrm{nMol}$ je g nachgewiesen werden (siehe 2.2). Die mit diesem gemeinsam eluierte Substanz konnte nicht identifiziert werden, ebenso nicht eine zweite, die in allen Honigen in geringer Menge gefunden wurde und die zwischen Cystathionin und Methionin eluiert wird.

Das Vorkommen von $\alpha$-Aminobuttersäure (Maslowski und MostowsKa, 1963) und von Äthanolamin (KoMAyINe, 1960) konnte nicht bestätigt werden. Nicht nachweisbar war auch Taurin, das im Königinnenfuttersaft (PratT und House, 1949) und in der Hämolymphe der Honigbiene (GLINSKI und Kostarz, 1968) gefunden worden war, und das nach Gilmour (1961) « in der Hämolymphe von Insekten weit verbreitet zu sein scheint m. Auch Lävulinsäure, deren Vorkommen in Honig (als Abbauprodukt von Hydroxymethylfurfural) denkbar erscheint - sie kann durch Ionenaustausch-Chromatographie unter den Bedingungen der Aminosäuren-Analyse ebenfalls bestimmt werden (Zacharius und Porter, 1967) - konnte nicht nachgewiesen werden.

\section{2. - Zuckerfütterungshonige}

Um den von der Biene stammenden Aminosäuren-Anteil im Honig zu erfassen, wurden von Bienen aus reiner Saccharose-Lösung erzeugte “ Honige ” untersucht. Die Proben $A_{1}$ bis $A_{11}$ wurden von demselben Volk durch Fütterung mit Zuckerlösung, ohne Eiweißzufuhr, gewonnen. Die Proben $R_{1}$ und $B_{2}$ wurden bei gleicher Ernährung, aber unterschiedlichen äußeren Bedingungen von einem zweiten Volk erhalten (siehe 2.1). In Tabelle A sind neben den Aminosäuren-Gehalten noch angegeben : der Zeitpunkt der Probeentnahme nach dem Beginn des Fütterungsversuchs, die jeweils gewonnene Menge, der Gesamtzuckergehalt (refraktometrisch bestimmt) und der Saccharosegehalt (polarimetrisch bestimmt nach der Zerstörung reduzierender Zucker mit Calciumhydroxid); (BEnRE und DürIng, 1922). 
Tabelle A. - Freie Aminosäuren in Zuckerf ütterungshonigen.

Obere Zahlenreihe: $\mathbf{n M o l} / \mathbf{g}$

Untere Zahlenreihe : Verhältniszahlen (s. 4. 1)

Tableau A. - Acides aminés libres dans les miels de nourrissement au sucre.

Série de chiffres supérieure : $\mathrm{nMol} / \mathrm{g}$

Série de chiffres inférieure : nombres proportionnels (Voir 4. 1)

\begin{tabular}{|c|c|c|c|c|c|c|c|c|c|c|c|c|c|}
\hline $\mathbf{A}$ & $\mathbf{A}_{1}$ & $\mathbf{A}_{2}$ & $\mathbf{A}_{3}$ & $\mathbf{A}_{4}$ & $\mathbf{A}_{5}$ & $\mathbf{A}_{8}$ & $\mathbf{A}_{\mathbf{7}}$ & $\mathbf{A}_{\mathbf{8}}$ & $\mathbf{A}_{9}$ & $\mathbf{A}_{10}$ & $\mathbf{A}_{11}$ & $\mathbf{B}_{1}$ & $\mathbf{B}_{2}$ \\
\hline $\begin{array}{l}\text { Probenentnahme } \\
\text { Tage nach Beginn. . }\end{array}$ & 3 & 5 & 10 & 13 & 17 & 20 & 24 & 27 & 34 & 48 & 55 & 4 & 30 \\
\hline \multicolumn{14}{|l|}{$\begin{array}{l}\text { Prélèvement de l'échan- } \\
\text { tillon. Nombre de jours } \\
\text { après le début ...... }\end{array}$} \\
\hline Menge $g$. $\ldots \ldots$ & 600 & 780 & 85 & 75 & 70 & 60 & 950 & 290 & 295. & 235 & 45 & 242 & 25 \\
\hline Quantité en $g$........ & & & & & & & & & & & & & \\
\hline Gesamtzucker \% .. & 77 & 77 & 75 & 73 & 70 & 72 & 74 & 76 & 80 & 81 & 81 & 62 & 62 \\
\hline \multicolumn{14}{|l|}{ Sucres totaux $\% \ldots \ldots$} \\
\hline Saccharose $\% \quad \ldots$ & 6 & 3 & $\mathbf{1}$ & 1 & $\mathbf{1}$ & 3 & 21 & 21 & 34 & 37 & 45 & 7 & 30 \\
\hline Ala $\ldots \ldots \ldots \ldots$ & 36 & 34 & 35 & 34 & 31 & 35 & 6 & 5 & 6 & 6 & 11 & 88 & 8 \\
\hline & 14 & 15 & 8 & 8 & 8 & 9 & 8 & 8 & 6 & 6. & 12 & 15 & 6 \\
\hline Arg $\ldots \ldots \ldots \ldots$ & 14 & 23 & 22 & 20 & 16 & 23 & 1 & 3 & 5 & 5 & 5 & 30 & 2 \\
\hline & $\mathbf{5}$ & 10 & 5 & 5 & 4 & 6 & 1 & 5 & 5 & 5 & 6 & 5 & 2 \\
\hline \multirow{2}{*}{$\begin{array}{l}(\mathbf{C y S})_{2} \\
\mathbf{G l n}+\operatorname{Asn} \ldots \ldots\end{array}$} & $\begin{array}{r}0 \\
81\end{array}$ & $\begin{array}{r}0 \\
40\end{array}$ & \begin{tabular}{r|r}
0 & \\
60 &
\end{tabular} & $\begin{array}{r}0 \\
60\end{array}$ & $\begin{array}{r}0 \\
79\end{array}$ & $\begin{array}{r}0 \\
45\end{array}$ & 0 & 0 & $\mathbf{0}$ & 0 & 0 & $\begin{array}{r}0 \\
130\end{array}$ & $\begin{array}{r}0 \\
10\end{array}$ \\
\hline & 31 & $\begin{array}{l}40 \\
18\end{array}$ & 14 & 14 & $\begin{array}{l}79 \\
19\end{array}$ & $\begin{array}{l}45 \\
12\end{array}$ & $\begin{array}{l}15 \\
21\end{array}$ & $\begin{array}{r}9 \\
14\end{array}$ & $\begin{array}{l}14 \\
15\end{array}$ & $\begin{array}{l}19 \\
19\end{array}$ & $\begin{array}{l}13 \\
15\end{array}$ & $\begin{array}{r}130 \\
22\end{array}$ & $\begin{array}{l}19 \\
15\end{array}$ \\
\hline \multirow{2}{*}{ His $\ldots \ldots \ldots \ldots$} & 28 & 30 & 48 & 44 & 40 & 39 & 4 & 4 & 5 & 3 & 3 & 46 & 3 \\
\hline & 11 & 14 & 11 & 10 & 10 & 10 & 6 & 6 & $\mathbf{5}$ & 3 & 3 & 8 & 2 \\
\hline \multirow{3}{*}{$\begin{array}{l}\text { Нур } \ldots \ldots \ldots \ldots \\
\text { Ile } \ldots \ldots \ldots \ldots \ldots\end{array}$} & 一 & - & - & - & 一 & - & - & - & - & - & 一 & $\begin{array}{r}34 \\
6\end{array}$ & $\begin{array}{l}9 \\
7\end{array}$ \\
\hline & 12 & 13 & 15 & 12 & 11 & 10 & 2 & 4 & 3 & 4 & 3 & 43 & 2 \\
\hline & 5 & 6 & 4 & 3 & 3 & 3 & 3 & 6 & 3 & 4 & 3 & 7 & 2 \\
\hline Leu........... & 11 & 13 & 10 & 8 & 5 & 4 & 1 & 2 & 2 & 2 & 3 & 24 & 1 \\
\hline \multirow{2}{*}{ Lys $\ldots \ldots \ldots \ldots$} & $\begin{array}{r}4 \\
4\end{array}$ & 6 & 2 & 2 & 1 & 1 & 1 & 3 & 2 & 2 & $\begin{array}{r}3 \\
18\end{array}$ & 4 & 0,8 \\
\hline & $\begin{array}{r}140 \\
54\end{array}$ & $\begin{array}{r}200 \\
91\end{array}$ & $\begin{array}{r}260 \\
62\end{array}$ & $\begin{array}{r}280 \\
64\end{array}$ & $\begin{array}{r}220 \\
54\end{array}$ & $\begin{array}{r}200 \\
53\end{array}$ & $\begin{array}{l}4 \\
6\end{array}$ & $\begin{array}{l}34 \\
53\end{array}$ & $\begin{array}{l}33 \\
35\end{array}$ & $\begin{array}{l}21 \\
21\end{array}$ & $\begin{array}{l}18 \\
20\end{array}$ & $\begin{array}{r}270 \\
47\end{array}$ & $\begin{array}{r}12 \\
9\end{array}$ \\
\hline \multirow{2}{*}{ Met.......... } & 1 & $\begin{array}{r}21 \\
2\end{array}$ & 2 & 2 & 2 & 3 & 1 & $\begin{array}{r}30 \\
1\end{array}$ & $\begin{array}{r}30 \\
1\end{array}$ & $\begin{array}{r}21 \\
1\end{array}$ & 1 & 0,5 & 0,1 \\
\hline & 0,4 & $\overline{\mathbf{1}}$ & $0, \overline{5}$ & $0, \overline{5}$ & $0, \overline{5}$ & 0,8 & 1 & $\mathbf{1}$ & 1 & 1 & 1 & & \\
\hline Orn $\ldots \ldots \ldots \ldots \ldots$ & - & - & - & - & - & - & - & - & - & - & -1 & \begin{tabular}{r|r}
15 \\
\end{tabular} & 7 \\
\hline \multirow{2}{*}{ Phe........... } & 27 & 30 & 40 & 36 & 35 & 31 & 4 & 6 & 5 & 2 & 4 & 74 & 2 \\
\hline & 10 & 14 & 10 & 8 & & 8 & 6 & 9 & 5 & 2 & 5 & 13 & 2 \\
\hline \multirow{2}{*}{ Pro $\ldots \ldots \ldots \ldots \ldots$} & 2600 & $\mid \begin{array}{ll}2 & 200\end{array}$ & 4200 & 4400 & 4100 & $\begin{array}{ll}3 & 800\end{array}$ & 730 & 640 & \begin{tabular}{|l|}
940 \\
\end{tabular} & $\mid \begin{array}{ll}1 & 000\end{array}$ & 870 & {$\left[\begin{array}{ll}5 & 800\end{array}\right]$} & 1300 \\
\hline & 1000 & $\begin{array}{ll}1 & 000\end{array}$ & 1000 & $\begin{array}{lll}1 & 0 & 0\end{array} \mid$ & $\begin{array}{ll}1 & 000\end{array}$ & 1000 & $\begin{array}{lll}1 & 0 & 0\end{array}$ & $\begin{array}{lll}1 & 000\end{array} \mid$ & 1000 & $\begin{array}{llll}1 & 000 & 1\end{array}$ & 1000 & 10001 & 1000 \\
\hline Ser $\ldots \ldots \ldots \ldots$ & 28 & $\mathbf{3 0}$ & 46 & 30 & 18 & 20 & 2 & $\mathbf{3}$ & 3 & 2 & 10 & 58 & 11 \\
\hline \multirow{2}{*}{ Thr $\ldots \ldots \ldots \cdots$} & 11 & 14 & 11 & 7 & 4 & 5 & $\begin{array}{l}3 \\
\mathbf{g}\end{array}$ & $\begin{array}{l}\mathbf{5} \\
\mathbf{9}\end{array}$ & 3 & 2 & 11 & 10 & 8 \\
\hline & $\begin{array}{r}18 \\
7\end{array}$ & $\begin{array}{r}10 \\
5\end{array}$ & $\begin{array}{r}31 \\
7\end{array}$ & $\begin{array}{r}26 \\
6\end{array}$ & $\begin{array}{r}18 \\
4\end{array}$ & $\begin{array}{r}15 \\
4\end{array}$ & $\begin{array}{r}8 \\
11\end{array}$ & $\begin{array}{r}8 \\
3\end{array}$ & $\begin{array}{l}7 \\
7\end{array}$ & $\begin{array}{l}6 \\
6\end{array}$ & $\begin{array}{l}11 \\
13\end{array}$ & $\begin{array}{r}37 \\
6\end{array}$ & $\begin{array}{l}2 \\
2\end{array}$ \\
\hline \multirow{2}{*}{$\operatorname{Trp} \ldots \ldots \ldots \ldots$} & 2 & 0 & 2 & 0 & 0 & 0 & 0 & 0 & 0 & 0 & 0 & 1 & 0 \\
\hline & 0,6 & & 0,4 & & & & & & & & & 0,2 & \\
\hline \multirow{2}{*}{ Tyr $\ldots \ldots \ldots \cdots$} & 10 & 14 & 13 & 10 & 9 & 10 & $\mathbf{l}$ & 2 & 2 & 2 & 3 & 32 & 1 \\
\hline & 4 & 6 & 3 & 2 & 2 & 3 & 1 & 3 & 2 & 3 & 3 & 6 & 1 \\
\hline Val $\ldots \ldots \ldots \ldots$ & 23 & 38 & 30 & 28 & 26 & 28 & 1 & 4 & 4 & 5 & 6 & 60 & 4 \\
\hline \multirow{2}{*}{$\begin{array}{l}\text { Summe der fr. Ami- } \\
\text { nosäuren } . . . \ldots \ldots\end{array}$} & & & & & & 7 & $\mathbf{1}$ & 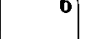 & 4 & 5 & 7 & 10 & 3 \\
\hline & $\begin{array}{ll}3 & 100\end{array}$ & $\begin{array}{lll}2 & 700\end{array}$ & $\begin{array}{ll}4800 \\
4\end{array}$ & $\begin{array}{ll}4900 \\
\end{array}$ & 4600 & 4300 & 780 & 720 & 1000 & $\begin{array}{ll}1 & 100\end{array}$ & 960 & $\mid \begin{array}{ll}6 & 700\end{array}$ & 1400 \\
\hline $\begin{array}{l}\text { Somme des acides ami- } \\
\text { nés libres ........... }\end{array}$ & & & & & & & & & & & & & \\
\hline
\end{tabular}


TABelle B. - Freie Aminosäuren in Futterzucker und in Honigblaseninhalt, Zuckerfütterungshonigen und Hämolymphe

Obere Zahlenreihe : $\mathbf{n ~ M o l} / \mathbf{g}$

Untere Zahlenreihe : Verhältniszahlen (s. 4. 1)

Tableau B. - Acides aminés libres dans le sucre de nourrissement et dans le contenu du jabot, le miel de nourrissement au sucre et l'hémolymphe

Série de chiffres supérieure : $\mathbf{n ~ M o l} / \mathbf{g}$

Série de chiffres inférieure : nombres proportionnels (Voir 4. 1)

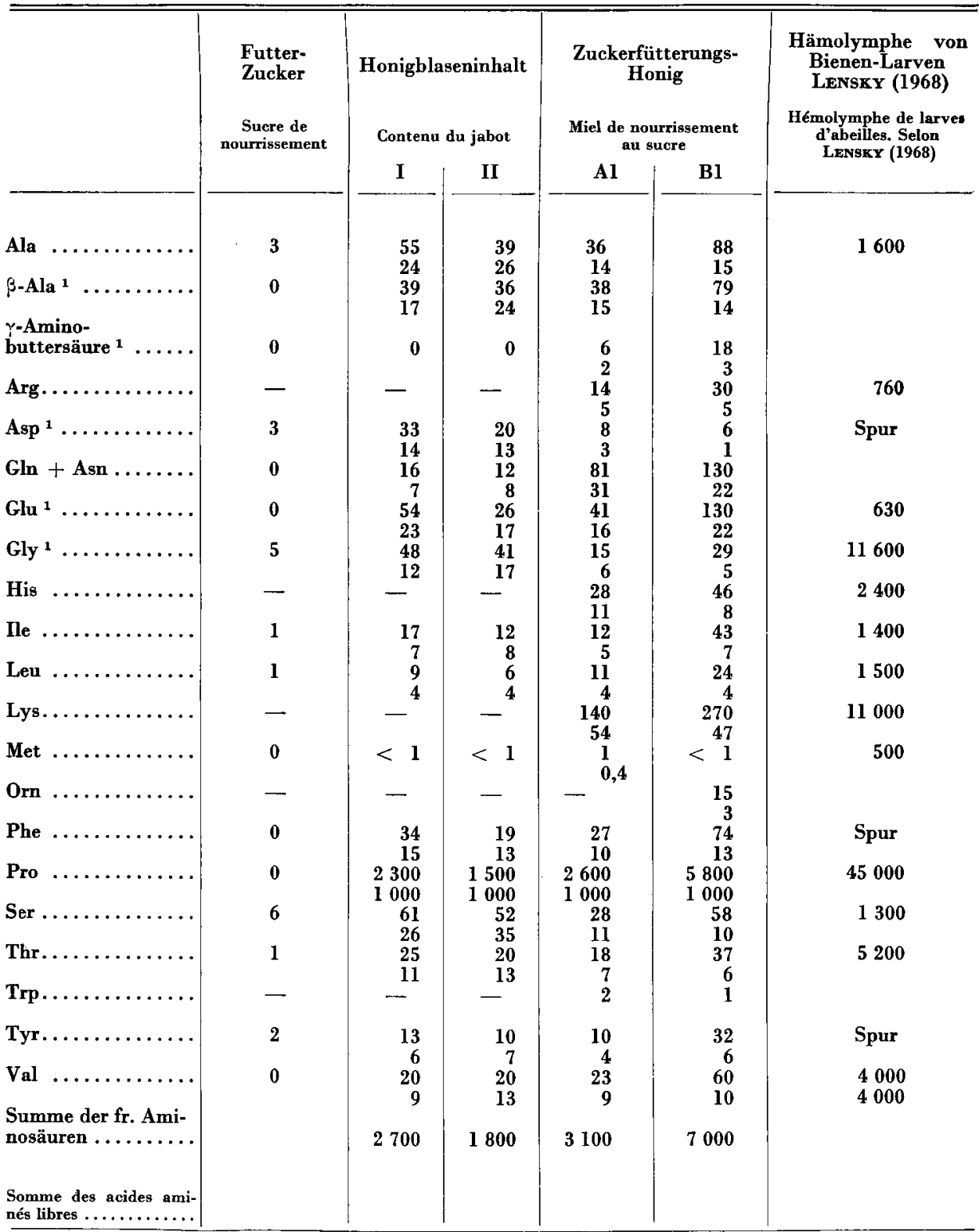

1. Uther Kationenaustauscher Harz abgetrennt. Séparés sur résine échangeuse de cations. 


\section{3. - Honigblaseninhalt}

Um festzustellen, ob von der Biene berejts während der Sammeltätigkeit Aminosäuren zugegeben werden, wurde der Honigblaseninhalt von Sammelbienen, die mit Zuckerlösung gefüttert worden waren, untersucht. Von denselben Bienen wurden nacheinander zwei Proben gewonnen (siehe 2.1), um eine Verfälschung des Ergebnisses durch vor Beginn des Versuchs in der Honigblase enthaltenem Honig zu verhindern. Die Aminosäuren-Gehalte (Tabelle B) sind auf einen Zuckergehalt von $80 \%$ berechnet, um den Vergleich mit den Zuckerfütterungshonigen $A_{1}$ und $B_{1}$ zu erleichtern. Auch der AminosäurenGehalt des verfütterten Zuckers (ebenfalls berechnet auf eine $80 \%$ ige Lösung) und, zum Vergleich, der Hämolymphe von Bienenlarven (nach LensKy, 1968) ist in Tabelle $B$ angegeben.

Da nur geringe Mengen Honigblaseninhalt gewonnen werden konnten, erfolgte ebenso wie bei Blüten-Nektar eine vereinfachte Aufarbeitung, über die an anderer Stelle berichtet wurde. (HahN, 1970; Bergner und HahN, 1972)

\section{$3.4-$ Honige}

Die untersuchten Honige waren - von wenigen Ausnahmen abgesehensogenannte “ Sortenhonige ». Darunter versteht man - entsprechend der

Tabelue C. - Freie Aminosäuren in Honig; Grenzwerte und Mittelwerte (n Mol/g)

Tableau C. - Acides aminés libres dans le miel; valeurs limites et valeurs moyennes ( $\mathrm{n}$ Mol $/ \mathrm{g}$ )

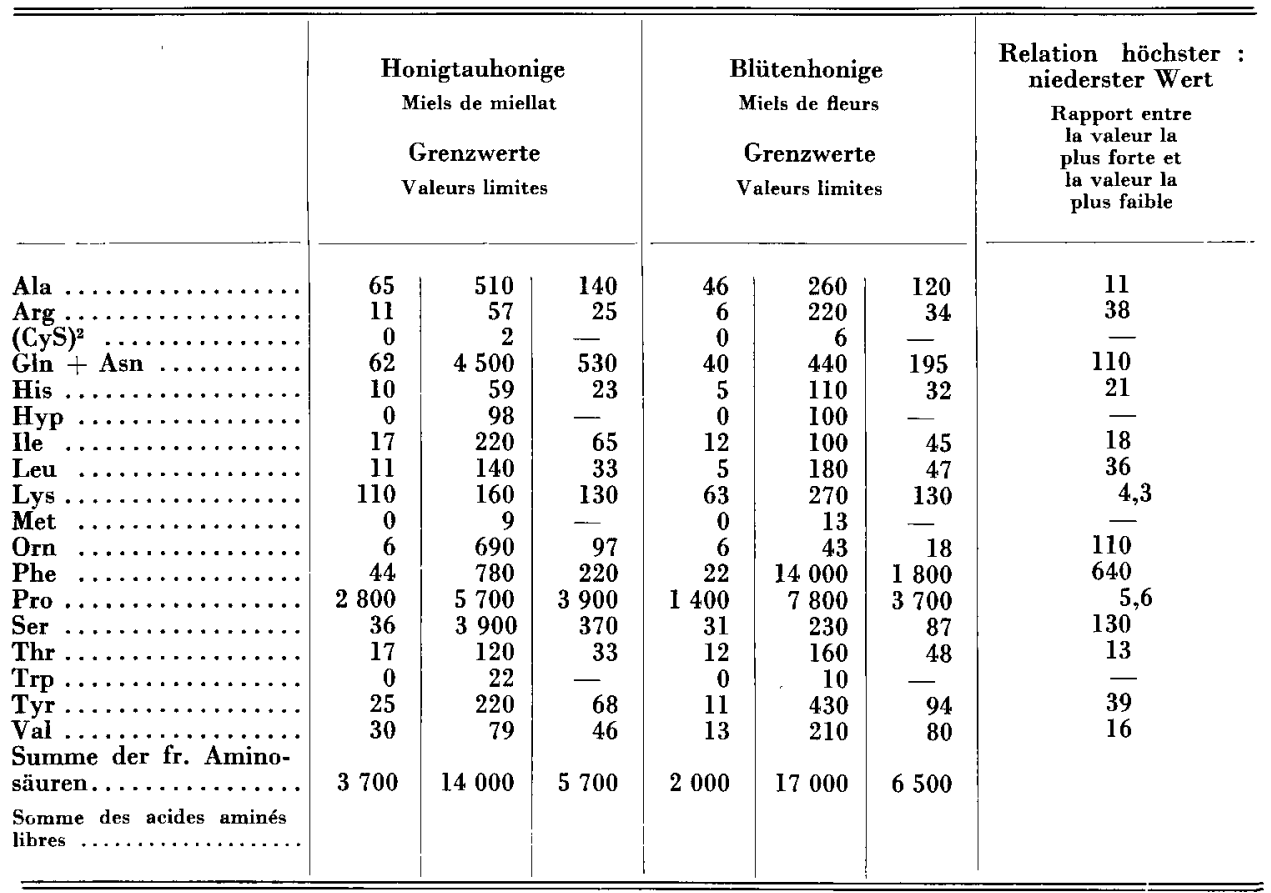


FREIE AMINOSÄUREN IN HONIG

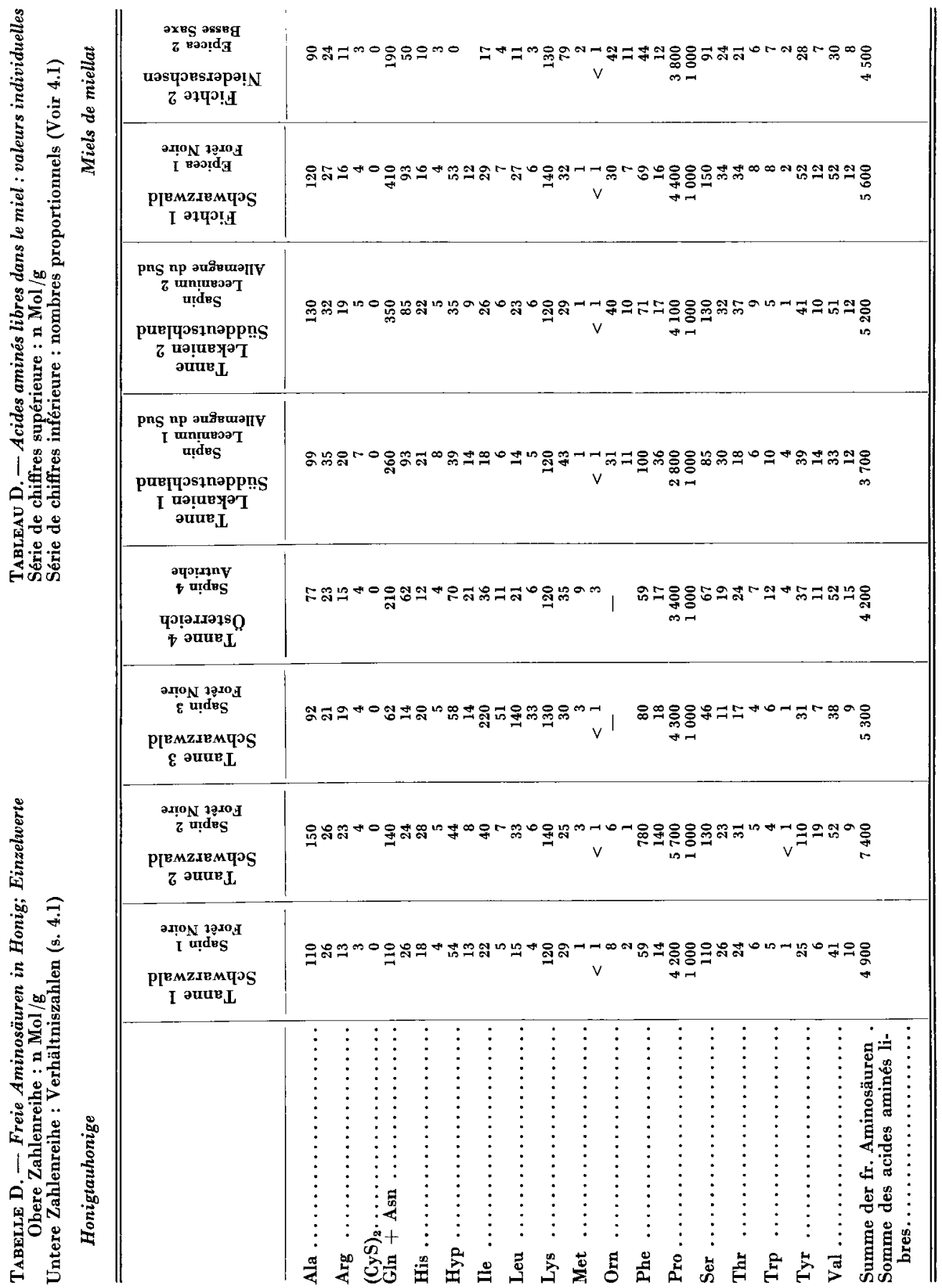




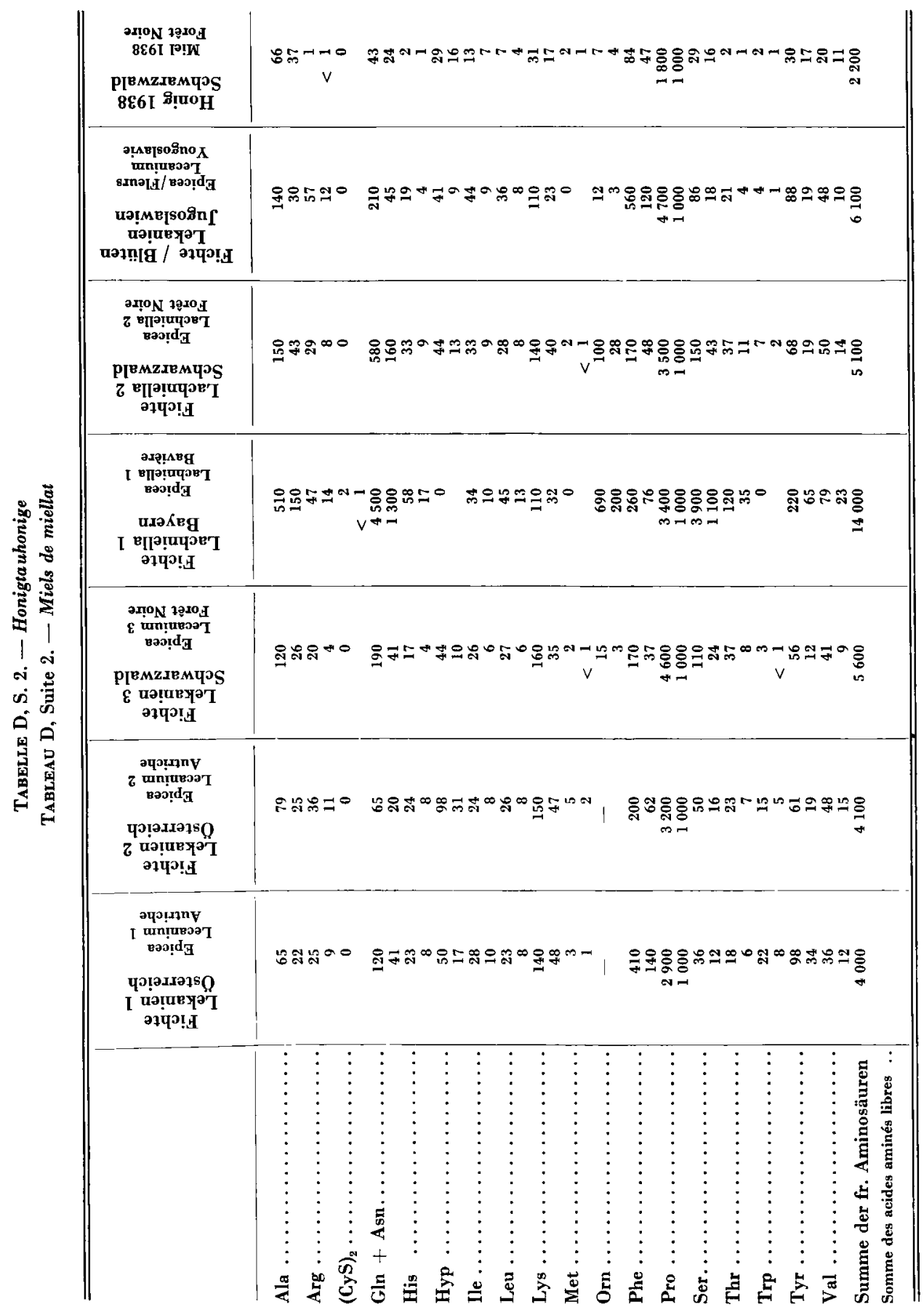




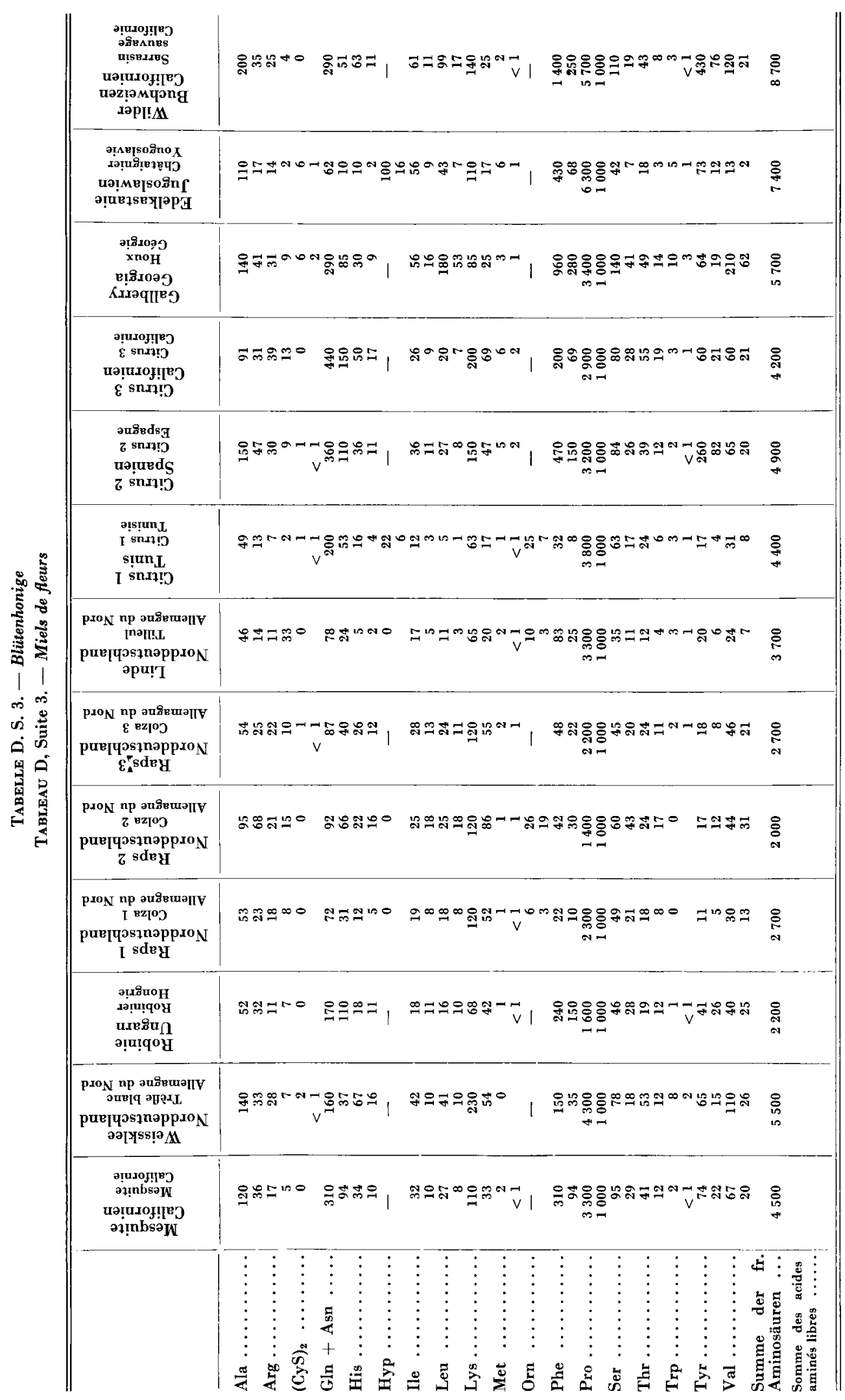




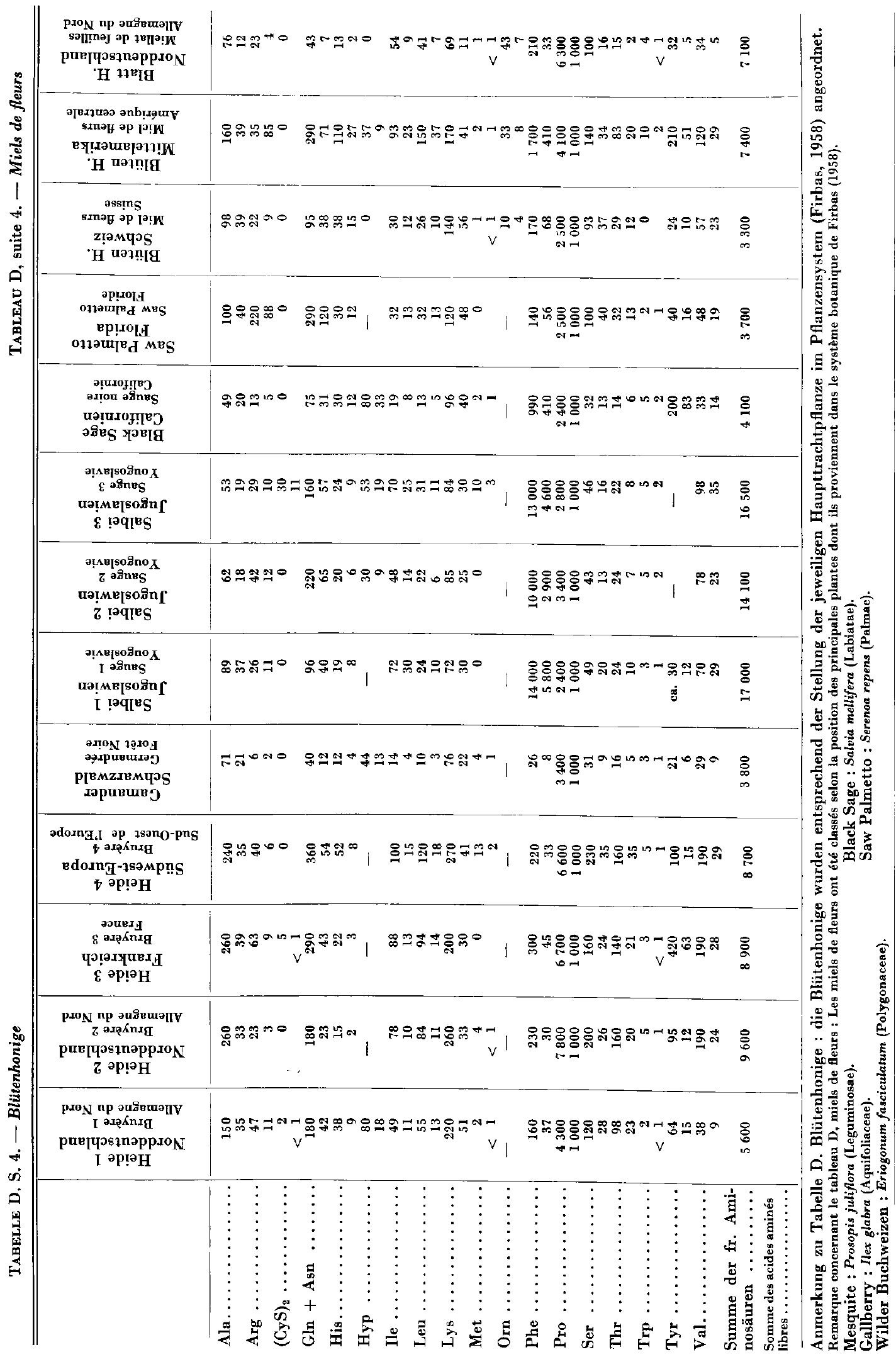


deutschen Honigverordnung - Honige, die c vorwiegend aus den Nektariensäften einer Bluitenart stammen "; auch Honigtauhonige werden, wenn sie üherwiegend auf einer Pflanzenart gesammelt worden sind, als Sortenhonige bezeichnet.

Waren bei den Honigtauhonigen Hinweise auf einen bestimmten Honigtauerzeuger bekannt, so wurde der Honig in Tabelle $D$ zusätzlich mit dem Namen des Insekts gekennzeichnet: In den mit “ Lekanie " bezeichneten Proben wurden bei der mikroskopischen Untersuchung des Sediments Wachsröhrchen der zu den Lekanien gehörenden Fichtenquirlschildlaus (Physokermes sp.) gefunden.

Ein hoher Melezitosegehalt eines Honigs weist nach Fossec (1969) dagegen auf Honigtau von Lachniella costata. (Die in Tabelle D entsprechend bezeichneten Proben enthielten etwa $20 \%$ Melezitose.) Über den Anteil des von diesen Insekten stammenden Honigtaus in den Proben kann jedoch nichts ausgesagt werden.

Die Grenzwerte und die Mittelwerte der einzelnen Aminosäuren sind - für Honigtauhonige und Blütenhonige getrennt - in Tabelle $\mathrm{C}$ angegeben. Tabelle D enthält die Einzelwerte von 14 Honigtau- und 25 Blütenhonigen.

Die einzelnen Aminosäuren sind in den untersuchten Honigen in außerordentlich unterschiedlicher Menge enthalten. Von den in mehreren Proben untersuchten Sortenhonigen sind auffällig die jugoslawischen Salbeihonige wegen ihres hohen Phenylalaningehalts (Bergner und Hahs, 1972 a), die Heidehonige wegen ihres insgesamt hohen und die Rapshonige wegen ihres insgesamt niedrigen Aminosäuregehalts.

Da die untersuchten Proben nicht zufällig, sondern gezielt ausgewählt wurden, stellen sie - statistisch gesehen - kein repräsentatives Teilkollektiv dar; allgemeine Durchschnittswerte oder Grenzwerte für den Aminosäurengehalt von Honig können deshalb nicht angegeben werden. Für eine statistische Untersuchung der einzelnen Honigsorten ist die Zahl der jeweils von derselben Sorte untersuchten Honige noch zu klein.

Innerhalb der untersuchten Proben wurde eine mittlere lineare Korrelation zwischen Phenylalanin- und Tyrosingehalt und eine starke lineare Korrelation zwischen Leucin- und Isoleucingehalt festgestellt :

Korrelations-

Koeffizienten
Honigtauhonige

$+0,52$
$+0,98$
$+0,76$
Honigtau- und Blütenhonige
Phe - Tyr $\ldots \ldots \ldots \ldots \ldots \ldots \ldots$

Leu - Ile ...............

Leu - Ile, ohne Tanne $3 \ldots \ldots$
Blütenhonige

0,62
$+0,73$
$+0,62$

$+0,73$

$+0,75$

Die Berechnung der Korrelationskoeffizienten erfolgte nach HAsELoFf und HoFfmanN (1965). Für Leucin - Isoleucin wurden auch die Koeffizienten ohne den Honigtauhonig "Tanne 3 " errechnet, da dieser durch seinen hohen Leucin- und Isoleucingehalt den Koeffizienten für die Honigtauhonige sehr stark beein flußt.

Die Korrelation zwischen Phenylalanin und Tyrosin ist wegen der Verknüpfung dieser Aminosäuren im Stoffwechsel verständlich. Für die Korrelation Leucin - Isoleucin fehlt jedoch eine Erklärung. 


\section{IV. - HERKUNFT DER FREIEN AMINOSÄUREN IN HONIG}

\section{1. - Der von der Biene stammende Anteil}

Der Aminosäure-Gehalt der Zuckerfütterungshonige $A_{1}$ bis $A_{11}$ (Tabelle A) nimmt insgesamt ab. Zurückzuführen ist dies wohl auf die eiweißfreie Ernährung des Bienenvolks. Gleichzeitig ist jedoch der Aminosäure-Gehalt einer Probe um so größer, je weniger Zuckerfütterungshonig vom Volk erzeugt wurde (vergl. in Tabelle $A$ : $A_{1}$ und $A_{2}$ gegen $A_{3}$ bis $A_{6}$ und gegen $A_{7}$ ). Das entspricht der Feststellung von Maurizio (1965), wonach Honige aus Massentrachten im allgemeinen einen geringeren Gehalt an von den Bienen stammenden Enzymen aufweisen.

Auch Zuckerfütterungshonig $B_{2}$ ist ärmer an Aminosäuren als $B_{1}$; der Gehalt von $B_{1}$ ist jedoch mehr als doppelt so groß wie derjenige der vergleichbaren Probe $A_{1}$. Auffällig ist aber, daß der prozentuale Anteil der einzelnen Aminosäuren an der Summe der freien Aminosäuren in beiden Proben nahezu gleich ist.

Als Bezugsgröße für weitere Berechnungen wurde jedoch nicht die Summe der freien Aminosäuren, sondern der Prolingehalt des jeweiligen Honigs verwendet, um von der Anzahl der im Einzelfall bestimmten Aminosäuren unabhängig zu sein (etwa bei Vergleich mit Ergebnissen anderer Autoren), und weil die Prolinbestimmung mit dem geringsten Fehler behaftet ist. Die Zweckmäßigkeit von Prolin als Bezugsgröße fand später eine Bestätigung (siehe 4.2).

Um diese relativen Aminosäuren-Gehalte - sie werden als « Verhältniszahlen » bezeichnet - in Form von ganzzahligen Werten zu erhalten, wurde Prolin $=1000$ gesetzt. Die Berechnung erfolgte nach der Gleichung :

Dabei ist :

$$
\mathrm{V}_{\mathrm{H}, \mathrm{As}}=\frac{\mathrm{G}_{\mathrm{H}, \mathrm{As}} \cdot \mathbf{1 0 0 0}}{\mathrm{G}_{\mathrm{H}, \mathrm{PrO}}}
$$

$\mathrm{V}_{\mathrm{H}, \mathrm{As}}=$ Verhältniszahl der Aminosäure As im Honig $\mathrm{H}$.

$\mathbf{G}_{\mathrm{H}, \mathrm{As}}=$ Gehalt des Honigs $\mathrm{H}$ an der Aminosäure As.

$\mathbf{G}_{\mathrm{H}}$, Pro $=$ Prolingehalt des Honigs $\mathbf{H}$.

Auch die so errechneten Verhältniszahlen sind für die Zuckerfütterungshonige $A_{1}$ und $B_{1}$ nahezu gleich (Tabelle B).

Nach Untersuchungen von Gontarski und Hoffmans (1962/63) wird von den Bienen während der Honigbereitung — sowohl bei der Sammeltätigkeit als auch beim aktiven Eindikken im Stock - Sekret der Pharynxdrüse zugegeben. Zu einer Zugabe von viel Sekret werden die Bienen veranlaßt durch eine hohe Zuckerkonzentration der Tracht, durch leckend-saugende Futteraufnahme und durch eine lange Dauer des aktiven Eindickungsprozesses (experimentell erreicht durch hohe Luftfeuchtigkeit im Stock).

Die übereinstimmenden Verhältniszahlen der Zuckerfütterungshonige deuten auf gleiche Zusammensetzung des Pharynxdrüsensekrets hin, die unterschiedlichen Absolutwerte auf eine unterschiedliche Menge zugesetzten Sekrets. 
Die den Bienen während der Bereitung von $A_{1}$ und $B_{1}$ angebotene Zuckerlösung hatte dieselbe Konzentration, die Nahrungsaufnahme dürfte daher in beiden Fällen gleichartig erfolgt sein. Die relative Luftfeuchtigkeit betrug bei $A_{1}$ etwa $40 \%$ (Bienenflugraum). $B_{1}$ wurde bei überwiegend veränderlichem Wetter und damit höherer Luftfeuchtigkeit bereitet (relative Luftfeuchtigkeit an den Sammeltagen, gemessen um 12.00 Uhr : 69; 55; 37;61;81\%). Mit der bei $B_{1}$ deshalb wohl längeren Dauer der aktiven Eindickung stehen die höheren Absolutwerte in Einklang.

Die im Honigblaseninhalt unmittelbar nach der Futteraufnahme (überwiegend leckend-saugend; Zuckergehalt ca. $80 \%$ ) gefundenen AminosäurenMengen (Tabelle B) zeigen, daß ein wesentlicher Anteil der im Zuckerfütterungshonig enthaltenen Aminosäuren bereits bei der Sammeltätigkeit zugegeben wird.

Die Verhältniszahlen der Aminosäuren-Gehalte von Honigblaseninhalt und Zuckerfütterungshonig liegen für die meisten Aminosäuren noch innerhalb des durch die Analysenfehler bedingten Streubereichs (Haнn 1970). Die Zusammensetzung der bei der Sammeltätigkeit und der beim aktiven Eindicken zugegebenen Sekrete dürfte sich deshalb wohl nicht wesentlich unterscheiden.

Gontanski und Hoffmann (1962/63) beobachteten eine Sekretzugabe von etwa $12 \%$ unter Bedingungen, die mit jenen bei der Gewinnung des Honigblaseninhalts vergleichbar sind (überwiegend leckend-saugende Aufnahme, Zuckerkonzentration 72 bis $74 \%$ ). Die Konzentration der einzelnen Aminosäuren müßte demnach im zugegebenen Sekret etwa 8 mal größer sein als im Honigblaseninhalt.

Angaben über den Aminosäuren-Gehalt des Pharynxdrüsensekrets sind in der Literatur nicht aufzu finden. Lediglich in Königinnen-Futtersaft, einem Gemisch der Sekrete von Pharynx - und Mandibeldrüse, wurden qualitativ $17 \alpha$ - Aminosäuren nachgewiesen (Emanuilow et al., 1963; RemboLd, 1964). Quantitative Bestimmungen wurden nicht durchgeführt, jedoch stellten Prate und House (1964) “ verhältnismäßig große Mengen an freiem Prolin 》 fest. DE Groot (1953) beobachtete eine wachstumsfördernde Wirkung des Prolins auf junge Bienen.

Die in der Hämolymphe von Bienenlarven enthaltenen freien Aminosäuren wurden von Lensky (1968) bestimmt. Der Prolingehalt ist danach etwa 20 bis 30 mal höher als in Honigblaseninhalt 1 und 2 (Tabelle B). Wenn auch der Aminosäuren-und besonders der Prolin-Gehalt der Hämolymphe beim Verpuppen abnimmt (GILmour, 1961, untersucht an Calliphora, Schmeißfliege), so ist trotzdem die für das Pharynxdrüsensekret abzuleitende hohe Prolinkonzentration denkbar.

Der hohe Prolingehalt der Hämolymphe von Insekten wird in Zusammenhang gebracht :

1. mit dem bedeutenden Anteil des Prolins am Cuticular-Protein, (Gilmour, 1961),

2. mit dem aeroben Muskelstoffwechsel (KInsten et al. 1963); dabei wird Prolin ïber Glutamat zu Ketoglutarat desaminiert, das seinerseits im Citrat-Zyklus abgebaut wird (GILMOUR, 1965). 
Innerhalb der Zuckerfütterungshonige $A_{1}$ bis $A_{11}$ - also während dre eiweißfreien Ernährung des Bienenvolks - werden die Verhältniszahlen der einzelnen Aminosäuren etwas kleiner, d.h. der prozentuale Anteil des Prolins an der Summe der freien Aminosäuren nimmt zu.

\begin{tabular}{|c|c|c|c|c|c|c|c|c|c|c|c|}
\hline $\mathbf{A}_{\mathbf{1}}$ & $\% \underset{\mathbf{A}_{2}}{\operatorname{Pr}}$ & $\begin{array}{c}\text { der } \\
A_{3}\end{array}$ & $\underset{\mathbf{A}_{4}}{\mathbf{m m e}}$ & $\begin{array}{r}\mathbf{r} \mathbf{f r} \\
\mathbf{A}_{5}\end{array}$ & $\underset{\mathbf{A}_{6}}{\mathbf{A m}_{\mathrm{m}}}$ & $\begin{array}{c}\text { säur } \\
\mathbf{A}_{\imath}\end{array}$ & $\mathbf{A}_{\mathrm{s}}$ & $\mathbf{A}_{9}$ & $\mathbf{A}_{10}$ & $\mathbf{A}_{11}$ & $\mathrm{~B}_{1}$ \\
\hline 84 & 82 & 87 & 88 & 89 & 89 & 94 & 88 & 91 & 93 & 91 & 86 \\
\hline
\end{tabular}

Unterschiede zwischen den für die Bienen essentiellen und den nichtessentiellen Aminosäuren (DE Groot, 1953) konnten nicht festgestellt werden.

Zusammenfassend kann über den Aminosäuren-Gehalt von Zuckerfütterungshonig und damit wahrscheinlich auch über den von der Biene stammenden Anteil der Aminosäuren in Honig gesagt werden :

1. die absoluten Aminosäuren-Mengen schwanken in ziemlich weiten Grenzen ( $>1: 2$ ). Die sind abhängig von der von der Biene zugegebenen Sekretmenge und damit von den Bedingungen während der Sammeltätigkeit und während des aktiven Eindickungsprozesses.

2. Die Mengen der Aminosäuren stehen zueinander in einem festen Verhältnis. Da sie nur von der Biene stammen, muß dieses Verhältnis im Zuckerfütterungshonig und im zugegebenen Sekret gleich sein.

3. In verschiedenen Zuckerfütterungshonigen sind die Mengen der einzelnen Aminosäuren proportional zur jeweils zugegebenen Sekretmenge.

4. Bei einer extrem eiweißarmen Ernährung des Volks verändern sich die Verhältniswerte etwas zugunsten von Prolin.

\section{2. - Der aus der Tracht stammende Anteil}

Grundlagen für eine Berechnung des Tracht-Anteils

Die Untersuchung der Zuckerfütterungshonige hat ergeben, daß die Bienen bei der Honigbereitung unterschiedliche Aminosäuren-Mengen zur Tracht zugeben. Eine einfache Beziehung zwischen den Aminosäuren-Gehalten von Tracht und daraus bereitetem Honig ist demnach nicht zu erwarten. Nur wenn der Tracht-Anteil einer Aminosäure sehr groß ist, wird er sich im Honig unmittelbar zeigen (z.B. Phenylalanin bei den jugoslawischen Salbeihonigen; Bergner und Hahn, 1972 a).

Die von der Biene zugegebenen Aminosäuren-Mengen, die im Honig den Aminosäuren-Gehalt der Tracht überlagern, müssen sich jedoch unter den beiden Voraussetzungen errechnen lassen, daß

1. das Pharynxdrüsensekret stets die gleiche relative AminosäurenZusammensetzung besitzt, 
2. der von der Biene stammende Anteil wenigstens einer Aminosäure bekannt ist.

Zu 1 : Da es sich bei dem Sekret um ein physiologisches Produkt handelt, ist anzunehmen, daß seine Zusammensetzung nicht beliebig, sondern nur in c biologischen Grenzen w schwanken kann (vergleichbar etwa der Zusammensetzung von Milch). Die bei den Zuckerfütterungshonigen gemachten Beobachtungen scheinen diese Voraussetzung zu bestätigen.

Zu 2 : Für praktische Zwecke wird auch der Gehalt einer Aminosäure, die überwiegend von der Biene stammt, ausreichen.

Die im Zuckerfütterungshonig und damit auch im Drüsensekret in weitaus größter Menge enthaltene Aminosäure ist Prolin, das zur Berechnung des von der Biene stammenden Aminosäuren-Anteils verwendet-wurde. Es wurde zwar auch in Nektar (Lüttge, 1961, Maslowski und Mostowska, 1963) und in Honigtau (Maltais und Auclair, 1952; Gray, 1952) nachgewiesen, die Berechnung wird jedoch nur dann verfälscht, wenn der Prolingehalt der Tracht ebenfalls sehr hoch ist.

Außerdem sprach noch folgende Überlegung für die Verwendung von Prolin als Bezugsgröße : In Zuckerfütterungshonigen sind die Mengen der einzelnen Aminosäuren proportional zur jeweils zugegebenen Sekretmenge (siehe 4.1). Daraus folgt, daß in einem Teilkollektiv von Zuckerfütterungshonigen (wenn vorstehende Voraussetzung 1 erfüllt ist) der Honig mit der größten Sekretzugabe jeweils die größte, derjenige mit geringster Sekretzugabe jeweils die kleinste Menge jeder Aminosäure enthält. Die Relation zwischen höchstem und niedrigstem Gehalt wird innerhalb des Teilkollektivs für alle Aminosäuren gleich sein.

Bei einem Teilkollektiv von normalen Honigen werden diese Relationen für diejenigen Aminosäuren größer, die in größerer Menge in mindestens einer Tracht enthalten waren. In Tabelle $\mathrm{C}$ sind diese Relationen für die untersuchten Honige angegeben. Die niedrige Relation für Prolin (nur die Lysin-Relation ist noch kleiner) deutet darauf hin, daß der Tracht-Anteil von Prolin - verglichen mit dem anderer Aminosäuren - klein ist.

Die von der Biene stammende Menge $M_{B}$ einer Aminosäure As ergibt sich aus der Gleichung :

1.

$$
\mathbf{M B}_{\mathbf{A} \mathrm{s}}=\frac{\mathbf{V}_{\mathrm{Zf}, \mathbf{A s}} \cdot \mathbf{M}_{\mathrm{Pro}}}{\mathbf{1 0 0 0}}
$$

Dabei ist :

$\mathrm{V}_{\mathrm{Zf}, A \mathrm{~s}}$ : die aus Zuckerfütterungshonigen berechnete Verhältniszahl der Aminosäure As (Tabelle B, Spalten 5 und 6)

$M_{\text {Pro }}$ : der Prolingehalt des Honigs

Die aus der Tracht stammende Menge $M_{T}$ der Aminosäure As ist dann :

2.

$$
\mathbf{M T}_{\mathbf{T}, \mathbf{A}_{\mathbf{s}}}=\mathbf{M r}, \mathbf{A}_{\mathbf{s}}-\mathbf{M B}_{\mathbf{B}} \mathbf{A}_{\mathbf{s}}
$$

$M_{H}, A s$ ist die im Honig enthaltene Menge der Aminosäure As.

In diese Berechnung gehen vier Aminosäuren-Bestimmungen mit ihren erheblichen Fehlern ein. Die vorliegenden Befunde führten daher nur im Falle der Rapshonige zu einem verwertbaren Ergebnis. Eine Verbesserung ist durch die Bestimmung der Verhältniszahlen $V_{\mathrm{zf}, \mathrm{As}}$ aus vielen Zuckerfütterungshonigen möglich, wodurch der physiologisch bedingte Streubereich genauer erfaßt, der durch die Fehler bedingte Streubereich verringert und damit der Gesamtfehler bei der Berechnung der absoluten Mengen nach den Gleichungen (1) und (2) vermindert wird. 
In die oben erwähnten Verhältniszahlen gehen dagegen nur zwei Aminosäuren-Bestimmungen ein. Deshalb wurden für jeden Honig nur die Verhältniszahlen, bezogen auf Prolin $=1000$, ermittelt. In diesen macht sich allerdings ein geringer Gehalt der Tracht an einer Aminosäure nicht bemerkbar; ein höherer Anteil aus der Tracht bewirkt eine Erhöhung der Verhältniszahl. Untere Grenzwerte müßten die bei den Zuckerfütterungshonigen ermittelten Verhältniszahlen $V_{z f}$, As sein.

Weitere Untersuchungen sind nötig, um festzustellen, ob die Aminosäuren-Zusammensetzung der Pharynxdrüsensekrete der verschiedenen, zur Imkerei verwendeten Bienenrassen und -arten gleich ist, d.h. ob gleiche Verhältniszahlen verwendet werden können. Einen unterschiedlichen Fermentgehalt von Honigen, die unter gleichen Bedingungen von Apis mellifica bzw. Apis cerana eingetragen worden waren, hat VокwонL (1968) festgestellt.

Um zu untersuchen, ob aus den Verhältniszahlen auf die Tracht geschlossen werden kann, wurden diese - für jede Aminosäure getrennt entlang einer Skala durch je einen Punkt dargestellt, und zwar Honigtauhonige links, Blütenhonige rechts der Skalen (Abb. 1). Die Verhältniszahlen der Zuckerfütterungshonige $A_{1}$ und $B_{1}$ wurden mit + bezeichnet.

Die Verteilung der Verhältniszahlen entlang der Skalen ist bei den einzelnen Aminosäuren verschieden. Eine weite Streuung (wie etwa bei Glutamin oder Phenylalanin) läßt erkennen, daß der aus der Tracht stammende Anteil sehr unterschiedlich ist. Eine nur geringe Streuung (z.B. bei Arginin, Isoleucin und Leucin) deutet darauf hin, daß der von der Biene stammende Anteil überwiegt. Die Verhältniszahlen $A_{1}$ und $B_{1}$ bilden zwar keinen unteren Grenzwert, sie liegen jedoch fast immer deutlich tiefer als der am häufigsten vorkommende Wert (Modalwert).

\section{Blütenhonige}

Die graphische Auswertung der Verhältniszahlen soll am Beispiel der Heidehonige erläutert werden :

In Abb. 1 wurden die den Heidehonigen 1 his 4 zukommenden Werte besonders gekennzeichnet. Der durch Analysenfehler bedingte Streubereich ihres Mittelwerts (bei $95 \%$ Sicherheit) wurde ebenfalls eingezeichnet. Die Anordnung der Heidehonige zum Modalwert bzw. zu den Werten der Zuckerfütterungshonige $(+)$ zeigt, ob ein wesentlicher Anteil einer Aminosäure aus der Tracht stammt; dies ist bei Leucin und Threonin der Fall. Andere Aminosäuren scheinen nur in geringer Menge in der Heidetracht enthalten zu sein (z. B. Arginin und Histidin). Eine breite Streuung der Verhältniszahlen untereinander deutet auf große Unterschiede im Aminosäurengehalt der einzelnen Heidetrachten (z. B. Tyrosin).

Werden die ebenfalls in mehreren Proben untersuchten Salbei-und Citrushonige in gleicher Weise betrachtet, so sind - außer den hohen Phenyl- 


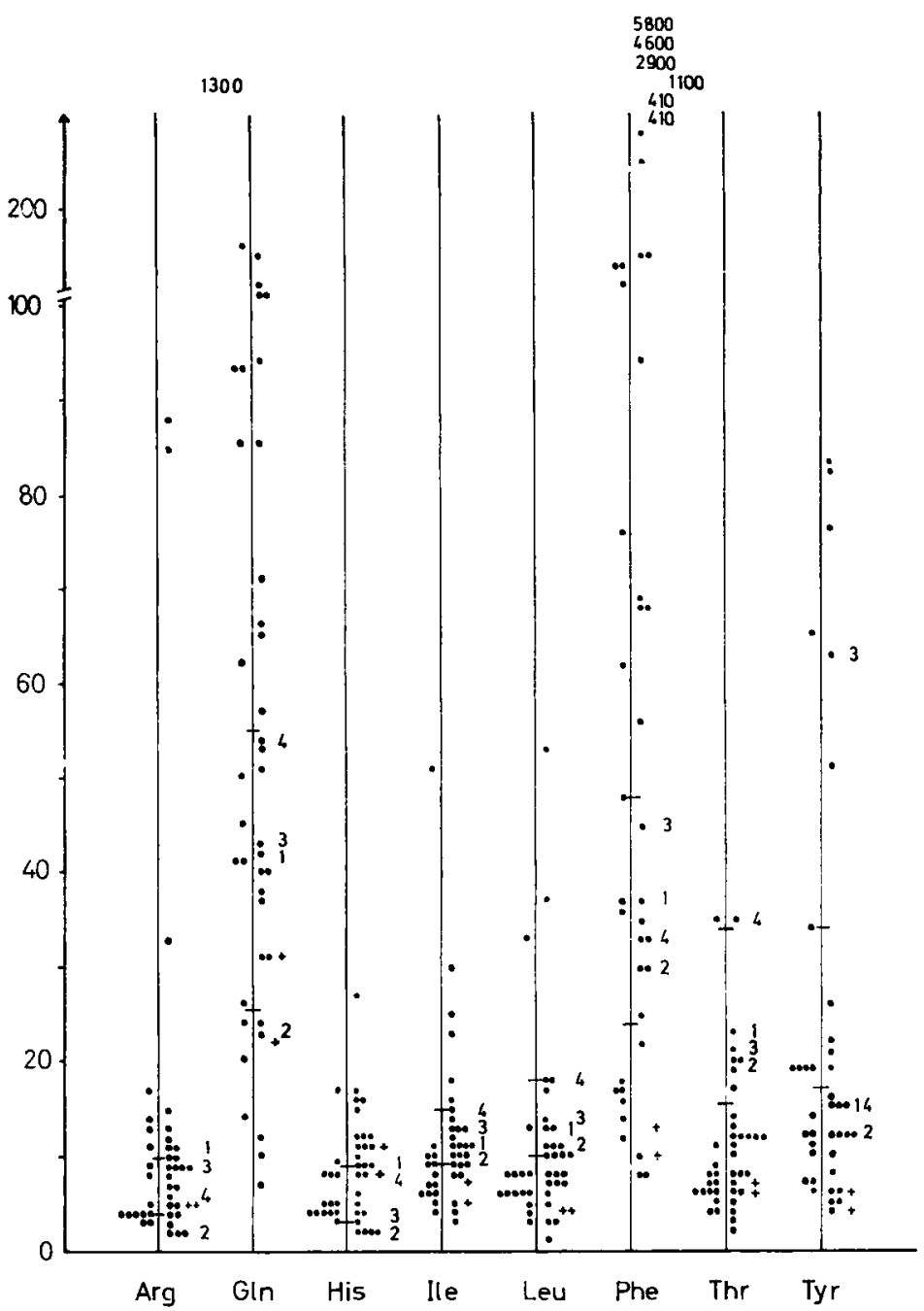

Aв8. 1. - Graphische Darstellung der Verhältniszahlen links : Honigtauhonige, rechts : Blütenhonige.

+ : Zuckerfütterungshonige $A_{1}$ und $B_{1}$.

$1=$ Heide $1, \quad 2=$ Heide 2 Streubereich ihres Mittelwertes.

$3=$ Heide 3, $4=$ Heide 4 (95\% Sicherheit).

FIG. 1. - Représentation graphique des nombres proportionnels.

A gauche : miels de miellat, à droite : miels de fleurs.

+ : miels de nourrissement au sucre $A_{1}$ et $B_{1}$.

$1=$ Bruyère $1, \quad 3=$ Bruyère 3 .

$2=$ Bruyère $2, \quad 4=$ Bruyère 4 .

Espace de dispersion de leurs valeurs moyennes (Sécurité $95 \%$ ). 
alanin-Verhältniszahlen der Salbeihonige - keine Beziehungen erkennbar, da die Werte entweder untereinander wesentlich stärker streuen oder in der Nähe des Modalwertes liegen (z. B. Histidin, Leucin, Threonin, Tyrosin bei den Salbeihonigen und Ieucin und Isoleucin bei den Citrushonigen).

Bei der U̇berprüfung, zu welchen Honigen die niedrigsten Verhältniszahlen gehören, stellte sich heraus, daß hierfür ganz überwiegend fünf, in Abb. 2 besonders markierte Honige verantwortlich sind. Fs ist anzunehmen,

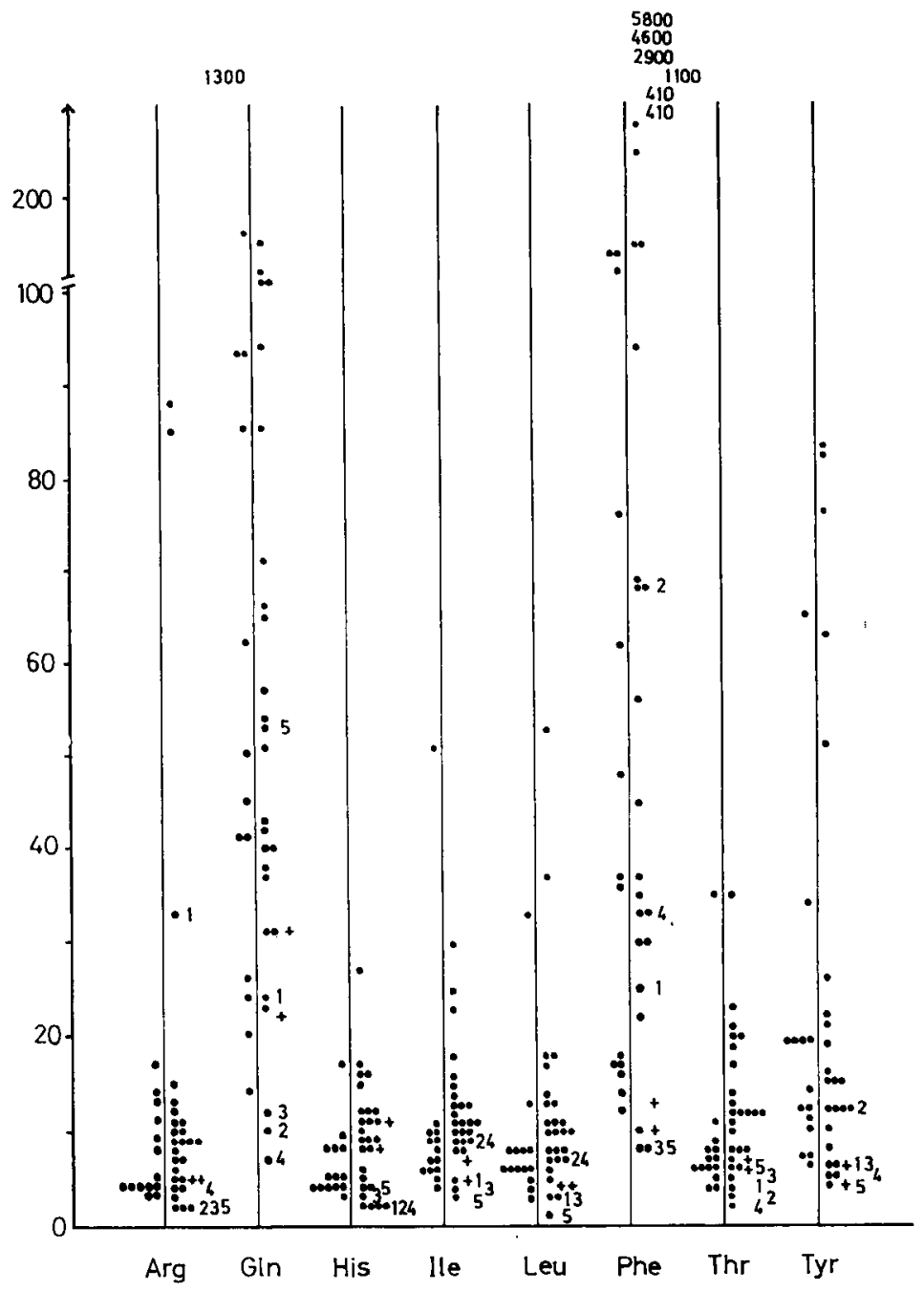

Aв8. 2. - Verhältniszahlen einiger Sortenhonige :

$1=$ Linde, $2=$ Edelkastanie, $3=$ Gamander, $4=$ Blatthonig, $5=$ Citrus 1.

Fig. 2. - Nombres proportionnels pour quelques miels unifloraux :

$1=$ Tilleul; $2=$ Châtaignier; $3=$ Germandrée: $4=$ Miellat de feuilles; $5=$ Citrus 1 . 
daß bei diesen Honigen in der Tracht Prolin enthalten war, wodurch eine größere Sekretzugabe vorgetäuscht wird, d. h. der aus der Tracht stammende Anteil aller Aminosäuren erscheint zu niedrig. Voraussetzung 2 (siehe oben) ist hier also nicht ausreichend erfüllt.

Für die Rapshonige wurden die von der Biene und die ans der Tracht. stammenden absoluten Mengen jeder Aminosäure nach den Gleichungen (1) und (2) berechnet. Dies ist hier möglich, da es sich um Honige von gut definiertem botanischen Ursprung handelt, denn zur Zeit der Rapsblüte ist kaum eine andere Tracht vorhanden. Der errechnete Aminosäurengehalt der drei Rapstrachten wurde in Abb. 3 dargestellt. Die dabei vereinzelt auftretenden negativen Werte sind wohl darauf zurückzuführen, daß die der Berechnung

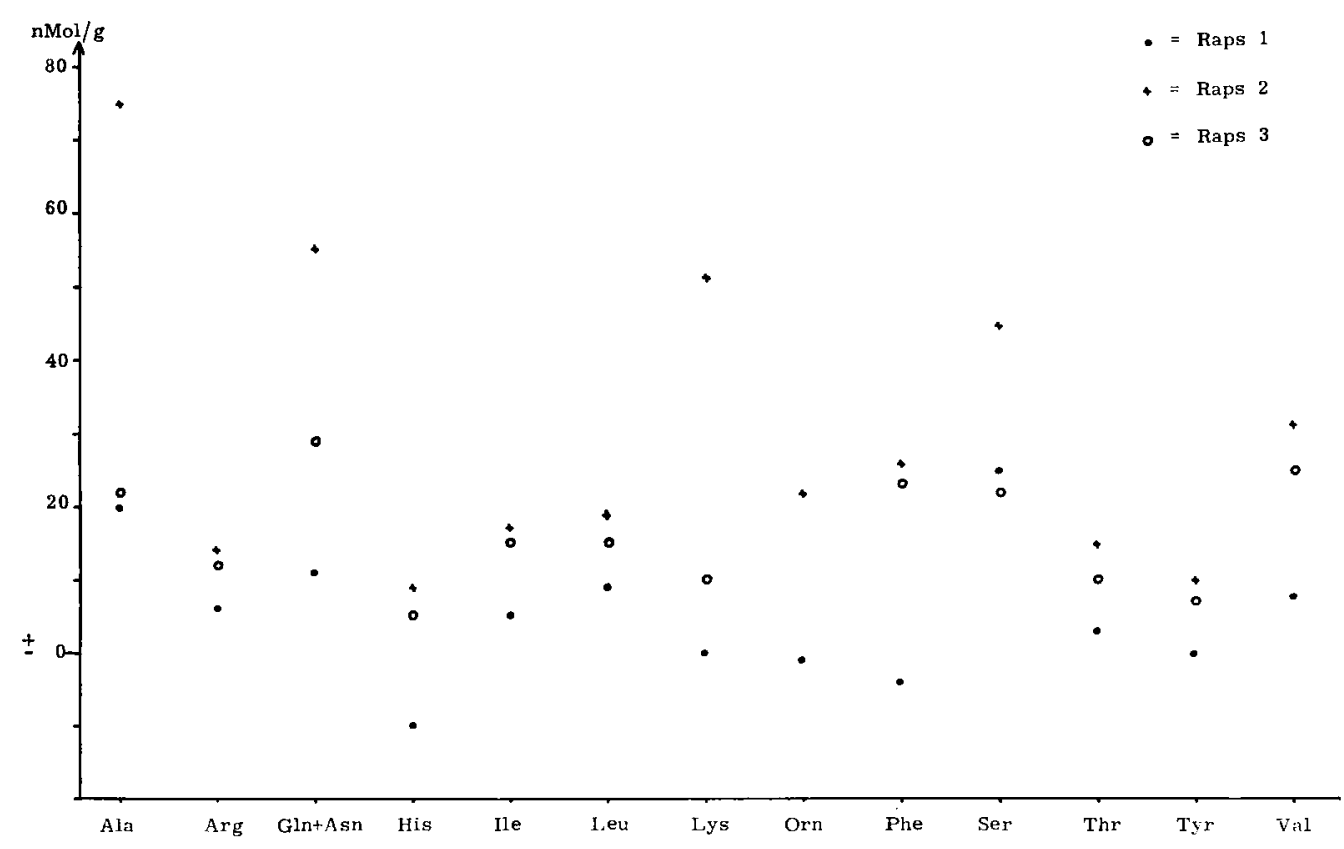

ABв. 3. - Errechneter Aminosäurengehalt der Rapstrachten (bezogen auf einen Zuckergehalt von $80 \%$ ).

Fig. 3. - Teneur calculée en amino-acides des miels de Colza (rapportëe à une teneur en sucres de $80 \%$ ).

zugrunde liegenden, aus nur zwei Versuchen ermittelten Verhältniszahlen der Zuckerfütterungshonige teilweise etwas zu hoch sind. Die Anordnung der Werte zeigt, daß die aus den Rapstrachten stammenden Aminosäuren-Mengen nicht gleich groß sind; sie könnte aber darauf hindeuten, daß die Trachtanteile - ebenso wie die von der Biene stammenden Mengen - in einem festen Verhältnis zueinander stehen. 
Eine zweite Erklärungsmöglichkeit wäre ein unterschiedlich hoher Prolingehalt der Rapstrachten. Nimmt man z. B. an, daß der Trachtanteil an Prolin in Rapshonig $2=0$ ist, so errechnet sich ein Trachtanteil an Prolin für Rapshonig 3 von ca. $40 \%$ (entsprechend $900 \mathrm{nMol} / \mathrm{g}$ Honig), für Rapshonig 1 von ca. $55 \%$ (entsprechend $1300 \mathrm{nMol} / \mathrm{g}$ Honig).

Welche der zwei Möglichkeiten zutrifft, wäre durch Untersuchung von mehreren, unter möglichst verschiedenen Bedingungen gewonnenen Nektarproben festzustellen. In beiden Fällen folgt aber aus dem Befund, daß der Aminosäurengehalt der Rapstracht stark schwanken kann.

\section{Honigtauhonige}

Die Modalwerte der Verhältniszahlen der Honigtauhonige (also der in Abb. 1 jeweils links der Skalen aufgetragenen Verhältniszahlen) liegen deutlich tiefer als diejenigen der Blütenhonige (rechts der Skalen). Ursache könnte ein nicht sehr hoher, in Honigtautrachten aber verbreiteter Prolingehalt sein. Es könnte sich jedoch auch um die Auswirkung eines Eiweißmangels im Bienenvolk handeln, vergleichbar dem während der Bildung der Zuckerfütterungshonige (vgl. Nr. 4 der Zusammenfassung von 4.1). So wird auch der während der Waldtracht oft zu beobachtende Rückgang der Bruttätigkeit auf einen Pollen- und damit Eiweißmangel zurückgeführt (HERoLd, 1960). Die Verhältniszahlen der Honigtauhonige deuten auf zum Teil sehr große Mengen einzelner Aminosäuren aus der Tracht hin (z. B. Glutamin/Asparagin, Ornithin und Serin bei den Fichte-Lachniella-Honigen und Isoleucin und Leucin bei Tanne 3). Die Unterschiede zwischen Honigtauhonigen vergleichbarer Tracht sind jedoch ebenfalls sehr groß, so daß aus den untersuchten Proben noch keine Zusammenhänge zwischen der Pflanze, dem Honigtauerzeuger und dem Aminosäurengehalt des Honigs abgeleitet werden können. Dafür verantwortlich ist auch die Tatsache, daß die beteiligten Honigtauerzeuger nur teilweise, ihre Anteile am Honig überhaupt nicht bekannt sind.

Nach Untersuchungen von ERHARD (1969) sind am Aminosäuren-Stoffwechsel der Honigtau liefernden Blattlaus Aulacortum circumflexum BuckT Darmsymbionten beteiligt, die alle für die Blattlaus essentiellen Aminosäuren zu synthetisieren vermögen. Möglicherweise ist also der Aminosäuren-Gehalt eines Waldhonigs das Ergebnis des Beitrags von 4 verschiedenen Organismen.

\section{3. - Folgerungen für die Honiganalyse}

Nach den vorliegenden Untersuchungen müßte aus dem Aminosäurengehalt bzw. den daraus berechneten Verhältniszahlen ein Hinweis auf reine Zuckerfütterungshonige zu erhalten sein. Mischungen von Zuckerfütterungshonigen oder eine Zuckerfütterung während der Trachtzeit werden sich aber kaum nachweisen lassen, besonders wenn der Honig- bzw. Trachtanteil einen hohen Aminosäurengehalt besitzt, da dann schon geringe 
Honig-bzw. Trachtmengen die Verhältniszahlen stark verändern können. Aus dem Aminosäurengehalt Hinweise auf einzelne Honigsorten (etwa jugoslawischen Salbeihonig) zu erhalten, erscheint grundsätzlich möglich. Doch muß erst durch wesentlich umfangreichere Untersuchungen festgestellt werden, welche Honigsorten sich so erkennen lassen.

\section{V. - HONIGPEPTIDE}

In den Aminosäurechromatogrammen (HAHN, 1970) von jugoslawischen Salbeihonigen fand sich zwischen Alanin und Valin ein breiter, keiner Aminosäure zuzuordnender Peak. Seine Fläche - zwecks Vergleichbarkeit berechnet als Leucin - entsprach in den Salbeihonigen 1, 2 und $3: 350$ bzw. 40 bzw. $120 \mathrm{nMol} / \mathrm{g}$. Die Abtrennung gelang durch Auffangen des Eluats der Trennsäule des Aminosäuren-Analysators vor der Ninhydrinzugabe. Durch Dialyse wurden zwei Fraktionen, A und B, erhalten, die nach saurer Hydrolyse die in Tabelle 3 angegebene Aminosäurenzusammensetzung zeigten.

Tabelle 3. - Peptide aus Salbeihonig

Tableau 3. - Peptides dans les miels de sauge

\begin{tabular}{|c|c|c|}
\hline & $\begin{array}{c}\text { Fraktion A } \\
\text { nicht dialysierbar } \\
\text { Mol \% } \\
\text { non dialysable }\end{array}$ & $\begin{array}{c}\text { Fraktion B } \\
\text { dialysierbar } \\
\text { Mol \% } \\
\text { dialysable }\end{array}$ \\
\hline Ala $\ldots \ldots \ldots \ldots \ldots \ldots \ldots \ldots \ldots \ldots \ldots$ & 8,3 & 15,7 \\
\hline B-Ala $\ldots \ldots \ldots \ldots \ldots \ldots \ldots \ldots \ldots$ & 0 & 0 \\
\hline 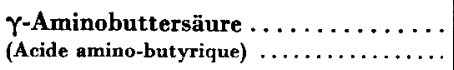 & 0 & $\mathbf{0}$ \\
\hline $\operatorname{Arg}(\ldots \ldots \ldots \ldots \ldots \ldots \ldots \ldots \ldots \ldots \ldots \ldots \ldots$ & 1,1 & $\mathbf{0}$ \\
\hline Asp $\ldots \ldots \ldots \ldots \ldots \ldots \ldots \ldots \ldots$ & 7,5 & 4,7 \\
\hline$(\text { Cys })_{2} \ldots \ldots \ldots \ldots \ldots \ldots \ldots \ldots \ldots$ & 0 & 0 \\
\hline Glu......................... & 154 & 0 \\
\hline Gly......................... & 20,4 & - \\
\hline His $\ldots \ldots \ldots \ldots \ldots \ldots \ldots \ldots \ldots \ldots \ldots \ldots \ldots$ & 3,3 & 0 \\
\hline nle $\ldots \ldots \ldots \ldots \ldots \ldots \ldots \ldots \ldots \ldots \ldots \ldots$ & 2,5 & 2,6 \\
\hline Leu $\ldots \ldots \ldots \ldots \ldots \ldots \ldots \ldots \ldots \ldots$ & 3,6 & 5,0 \\
\hline Lys $\ldots \ldots \ldots \ldots \ldots \ldots \ldots \ldots \ldots$ & 3,3 & 2,9 \\
\hline Met $\ldots \ldots \ldots \ldots \ldots \ldots \ldots \ldots \ldots \ldots$ & 0,9 & 0 \\
\hline Orn $\ldots \ldots \ldots \ldots \ldots \ldots \ldots \ldots \ldots$ & 0 & 0 \\
\hline Phe $\ldots \ldots \ldots \ldots \ldots \ldots \ldots \ldots \ldots \ldots \ldots$ & 4,2 & 41,4 \\
\hline Pro........................ & 0 & 0 \\
\hline Ser $\ldots \ldots \ldots \ldots \ldots \ldots \ldots \ldots \ldots$ & 17,3 & 9.7 \\
\hline Thr $\ldots \ldots \ldots \ldots \ldots \ldots \ldots \ldots \ldots \ldots$ & 5,8 & 4,2 \\
\hline Trp $\ldots \ldots \ldots \ldots \ldots \ldots \ldots \ldots$ & 0 & 0 \\
\hline Tyr $\ldots \ldots \ldots \ldots \ldots \ldots \ldots \ldots \ldots \ldots \ldots \ldots$ & 2,2 & 4,2 \\
\hline val $\ldots \ldots \ldots \ldots \ldots \ldots \ldots \ldots$ & 4,1 & 9,2 \\
\hline
\end{tabular}


Die Dialyse und Hydrolyse wurden nach einer Methode durchgeführt, die zur GesamtAminosäuren-Bestimmung in Honig ausgearbeitet worden war (BERGNER und HAHN, 1972 a). Weiter wurde ein alkalisches Hydrolysat nach Pataki (1966), S. 135, hergestellt. Tryptophan konnte auch darin nicht nachgewiesen werden.

Besonders auffällig ist der große Unterschied im Phenylalaningehalt der Fraktionen A und B. Warum sie bei der Aufarbeitung des Honigs vom KupferChelatharz (Hahn, 1970; Bergner und HahN, 1972) zusammen mit den Aminosäuren festgehalten werden, kann aus ihrer Zusammensetzung nicht erklärt werden (eine Ursache hätte z. B. ein hoher Gehalt an basischen Aminosäuren sein können).

Aus der jeweils in geringster Menge enthaltenen Aminosäure (Methionin bei A, Isoleucin bei B) errechnet sich als Molekulargewicht von Fraktion A ca. 13000 , von Fraktion B ca. 5500 beziehungsweise ein Vielfaches dieser Werte. Nach der Durchlässigkeitsgrenze des zur Dialyse verwendeten CelluloseSchlauchs (etwa Molekulargewicht 5000 ) ist für B ein Molekulargewicht von ca. 5500 anzunehmen.

Da in keinem anderen Honig - auch nicht im californischen Salbeihonig - an der entsprechenden Stelle des Chromatogramms ein Peak gefunden wurde, ist wahrscheinlich, daß $A$ und $B$ nur in der Tracht der jugoslawischen Salbeihonige enthalten waren. Im Nektar von Wiesensalbei, aus dem die Aminosäuren allerdings über einen Kationenaustauscher abgetrennt wurden (Bergner und Hahn, 1972 a), konnten diese Peptidfraktionen ebenfalls nicht nachgewiesen werden.

Es ist denkbar, daß durch die Untersuchung von Peptiden und Proteinen eines Honigs vielfältigere Hinweise auf die Art der Tracht erhalten werden können, als es durch die Bestimmung der Aminosäuren allein möglich ist. Weitere Untersuchungen in dieser Richtung sind im Gange.

\section{VI. - DAS VERHALTEN DER FREIEN AMINOSÄUREN WÄHREND DER HONIGLAGERUNG BEI ERHÖHTER TEMPERATUR}

Um den Einfluß von Temperaturen, wie sie etwa beim Umschmelzen von Honig verwendet werden, auf den Aminosäuren-Gehalt festzustellen, und um eine längere Lagerung bei Zimmertemperatur zu simulieren, wurde ein Rapshonig in verschlossenen Glasgefäßen bei $45^{\circ} \mathrm{C}$ gelagert. Der Aminosäurengehalt zu Anfang und nach 2,4 und 6 Wochen ist in Tabelle 4 angegeben.

Obwohl die aus den gelagerten Proben gewonnenen Aminosäuren-Extrakte stärker gefärbt waren, war nur eine geringe Abnahme der Aminosäuren festzustellen : mit Ausnahme von Ornithin lagen alle Werte noch innerhalb des statistischen Streubereichs ihres Mittelwerts (bei $95 \%$ Sicherheit).

Daß die Aminosäuren in Honig trotz der hohen Konzentration an reduzierenden Zuckern auch bei sehr langer Lagerung recht stabil sind, geht auch 
TABelle 4. - Verhalten der freien Aminosäuren während der Honiglagerung bei erhöhter Temperatur

TABLEAU 4. - Comportement des acides aminés libres pendant le stockage du miel à température élevée

\begin{tabular}{|c|c|c|c|c|}
\hline n $\mathrm{Mol} / \mathrm{g}$ & $\begin{array}{c}\text { Anfangs- } \\
\text { Gehalt } \\
\text { Teneur } \\
\text { initiale }\end{array}$ & $\begin{array}{c}\text { nach } 3 \text { Wochen } \\
\text { bei } 45^{\circ} \mathrm{C} \\
\text { après } 3 \text { semaines } \\
\text { à } 45^{\circ} \mathrm{C}\end{array}$ & $\begin{array}{c}\text { nach } 4 \text { Wochen } \\
\text { bie } 45^{\circ} \mathrm{C} \\
\text { après } 4 \text { semaines } \\
\text { à } 45^{\circ} \mathrm{C}\end{array}$ & $\begin{array}{c}\text { nach } 6 \text { Wochen } \\
\text { bei } 45^{\circ} \mathrm{C} \\
\text { après } 6 \text { semaines } \\
\text { à } 45^{\circ} \mathrm{C}\end{array}$ \\
\hline Alanin $\ldots \ldots \ldots \ldots \ldots$ & 71 & 84 & 78 & 79 \\
\hline $\operatorname{Arginin} \ldots \ldots \ldots \ldots \ldots$ & 20 & 22 & 19 & 17 \\
\hline Glutamin..$\ldots \ldots \ldots \ldots$ & 93 & 74 & 77 & 63 \\
\hline Histidin. . . . . . . . . & 25 & 22 & 22 & 14 \\
\hline Hydroxyprolin ......... & 8 & 8 & 8 & 8 \\
\hline Isoleucin $\ldots \ldots \ldots \ldots$ & 25 & 26 & 23 & 25 \\
\hline Leucin $\ldots \ldots \ldots \ldots$ & 25 & 24 & 21 & 24 \\
\hline Lysin $\ldots \ldots \ldots \ldots \ldots$ & 150 & 150 & 140 & 130 \\
\hline Methionin $\ldots \ldots \ldots \ldots$ & $<1$ & $<1$ & $<1$ & $<1$ \\
\hline Ornithin $\ldots \ldots \ldots \ldots \ldots$ & 17 & 12 & 9 & 11 \\
\hline Phenylalanin .......... & 44 & 50 & 43 & 47 \\
\hline Prolin...$\ldots \ldots \ldots \ldots$ & 2000 & 1900 & 1800 & 1700 \\
\hline Serin $\ldots \ldots \ldots \ldots \ldots$ & 61 & 74 & 70 & 70 \\
\hline Threonin $\ldots \ldots \ldots \ldots$ & 25 & 27 & 25 & 24 \\
\hline Tyrosin $\ldots \ldots \ldots \ldots \ldots$ & 21 & 20 & 18 & 20 \\
\hline Valin $\ldots \ldots \ldots \ldots \ldots$ & 41 & 42 & 40 & 44 \\
\hline
\end{tabular}

aus dem Aminosäurengehalt eines über 30 Jahre alten Honigs hervor (Tabelle D, Honigtauhonige, letzte Spalte : “ Honig 1938 »). Die mikroskopisch als Honigtauhonig identifizierte Probe war tiefdunkelbraun gefärbt, Geruch und Geschmack erinnerten an Rübenkraut. Der Gesamtgehalt an freien Aminosäuren (2 $200 \mathrm{nMol} / \mathrm{g}$ ) betrug noch etwa $40 \%$ des Durchschnittswertes der Waldhonige. Als Hinweis auf die lange Lagerung kann die sehr niedrige Verhältniszahl von Lysin angesehen werden, das als Diaminosäure bei nichtenzymatischen Bräunungsreaktionen (MAILlaRD-Reaktionen) schneller abgebaut wird als Monoaminosäuren. (Die innerhalb der übrigen $W$ aldhonige liegende Verhältniszahl von Ornithin widerspricht dem nicht, da der Ausgangsgehalt des Honigs nicht bekannt ist.)

Durch eine Aminosäuren-Untersuchung läßt sich also eine Wärmebehandlung oder eine lange Lagerung eines Honigs nicht nachweisen.

Eingegangen im November 1971.

Reçu pour publication en novembre 1971.

\section{DANK}

Wir danken der Landesanstalt für Bienenkunde, Stuttgart-Hohenheim, insbesondere ihrem Leiter, Herrn Dr. Steche sowie Herrn Dr. Vorwohl für die Beschaffung zahlreicher Honigproben und für viele wertvolle Hinweise. 


\section{RESUMÉ}

\section{Méthodes}

Hahn (1970), Bergner et Hahn (1972), ont déjà rendu compte de la mise au point d'une méthode permettant l'isolement des acides aminés libres du miel par séparation des hydrates de carbone, des peptides et des protéines au moyen d'une colonne cuivre-chélate ainsi que la détermination des acides aminés par la chromatographie automatique échangeuse d'ion selon Spackman, Stern et Moore.

\section{Obtention du matêriel expérimental.}

Miels de nourrissement au sucre. En ce qui concerne chacun des miels de nourrissement au sucre A et B, une petite colonie d'abeilles de race carniolienne (Apis mellifica carnica) a été installée sur des rayons bien centrifugés et exempts de pollen. On a ensuite opéré de la façon suivante :

- Miel de nourrissement au sucre A : installation de la colonie d'abeilles dans une chambre de vol (environ $3 \times 6 \mathrm{~m}$ ) à $23-26^{\circ} \mathrm{C}$ et environ $40 \%$ d'humidité relative. Éclairage artificiel au moyen de tubes fluorescents placés derrière un verre dépoli; période d'éclairement égale à la période obscure avec 30 minutes de pénombre (allumage ou extinction progressifs). Nourrissement des abeilles dans la ruche et à l'extérieur à environ $4 \mathbf{m}$ du trou de vol avec une solution de sucre $1: 2$.

- Miel de nourrissement au sucre $B$ : installation de la colonie d'abeilles à l'extérieur mais avec une " véranda " grillagée $(30 \times 30 \times 25 \mathrm{~cm})$ devant le trou de vol. Nourrissement avec une solution de sucre 1 : 2 à l'intérieur de la ruche et dans la “ véranda ».

Les miels de nourrissement au sucre $A_{1}, A_{2}, A_{7}$ furent recueillis par centrifugation; tous les autres par aspiration dans les cellules au moyen d'un tube capillaire relié à une trompe à eau. Contenu du jabot. Environ 40 butineuses (Apis mellifica carnica) furent capturées devant le trou de vol, mises à jeûner pendant à peu près une heure puis nourries avec une solution de saccharose à $80 \%$ environ. Les abeilles furent anesthésiées quelques instants au $\mathrm{CO}_{2}$ puis obligées à régurgiter le contenu de leur jabot par une légère pression sur l'abdomen (contenu du jabot $n^{\circ}$ 1). Ensuite, ces mêmes abeilles furent nourries encore une fois et le contenu du jabot récolté de la même façon que précédemment (contenu du jabot $\mathrm{n}^{\circ} 2$ ).

\section{Résultats}

1) Dans tous les miels on a pu déterminer de façon quantitative les acides aminés suivants : alanine, arginine, glutamine/asparagine (ensemble), histidine, isoleucine, leucine, lysine, phénylalanine, proline, sérine, thréonine, tyrosine et valine.

La cystine, la 4-hydroxyproline, la méthionine et le tryptophane n'ont été mis en évidence que dans une partie des miels (Tableaux $C$ et $D$ ).

2) En utilisant les miels de nourrissement au sucre on a pu étudier la part d'acides aminés libres ajoutée au miel par l'abeille. Pour des teneurs absolues en acides aminés différentes, les proportions de ces acides étaient remarquablement semblables (Tableau A). Ceci s'explique par l'addition par l'abeille à la nourriture de quantités variables de secrétions contenant des acides aminés.

3) L'examen du contenu du jabot des butineuses (Tableau B) montre que, déjà au cours de la récolte, se produit une addition d'acides aminés. C'est la proline qui est, de loin, ajoutée en plus grande quantité.

4) Une caractérisation des sortes de miel par leur contenu en acides aminés n'a été pos- 
sible, du fait de la variabilité des quantités ajoutées par l'abeille, que dans des cas très particuliers, par exemple dans le cas du miel de Sauge qui contient une quantité extraordinairement importante de phénylalanine.

5) Pour pouvoir déterminer l'origine botanique des autres miels au moyen de la teneur en acides aminés on a tenté de calculer à partir de la teneur en proline du miel la quantité de sécrétion ajoutée par l'abeille et ainsi, pour les différents acides aminés, la part de ceux-ci qui provient de l'abeille. En raison du nombre limité des miels de nourrissement au sucre examinés on n'a obtenu un résultat que pour les miels de colza (Fig. 3). Pour les autres miels la teneur relative en chacun des acides aminés rapportée à la proline $=1000$ a été calculée. Ce c nombre proportionnel " a été traduit graphiquement (Fig. 1 et 2). On a alors constaté que pour de nombreux acides aminés (par ex. glutamine, phénylalanine) il semble cependant que la part provenant de l'abeille soit dominante. L'attention est attirée sur le grand nombre de variables qui influent sur la teneur en acides aminés d'un miel, et tout particulièrement d'un miel de miellat.

6) Le cas d'un miel de Sauge montre qu'il est possible que les peptides ou les protéines puissent servir à la caractérisation des différentes sortes de miel.

7) Les modifications de la teneur en acides aminés des échantillons de miel conservés à une température élevée ne sont pas suffisamment importantes pour permettre la détection d'une dégradation du miel par la chaleur ou le stockage sur de trop longues périodes (Tableau 4).

\section{LITERATUR}

Auclair, J.-L., u. C.-A. Jamieson : Science (New York) 108, 357 (1948).

Baumgarten, F., u. J. Möckesch : Z. Bienenforsch. 3, 181 (1956).

Behre, A., u. A. Düring : Z. Unters. Lebensmittel 44, 65 (1922).

Bergner, K.-G., u. J. Körömi : Z. Bienenforsch. 9, 182 (1968).

Bergner, K.-G., und Hj. HAhN : Dtsch. Lebensmittel-Rdsch. 68, (1972) im Druck.

Bergner, K.-G., und Hj. Hahn : Z. Ernährungswiss. im Druck (1972a).

Blackburn, S. : Amico acid determination, M. Dekker Inc., New York, 1968.

de Boen, H.-W. : Chem. Weekbl. 43, 562; 578; 592 (1947) ref. : C. A. 42, 1675 e (1948).

Curti, R., u. V. Riganti : Rass. Chim. N. 6, 278 (1966).

Emanuilow, J., P. Welchewa, L. Nachew, A. Toshkow u. L. Shirowa : Bulgar. Akad. Nauk. 15, 89 (1963), ref. : C.A. 60, 16253 h (1964).

ErhaRDT, P. : Kongreßbericht XXII. Internat. Bienenzüchter-Kongreß München, 1969, Apimondia-V., Bukarest, 1969.

Fossec, A. : Kongreßbericht XXII. Internat. Bienenzüchter-Kongreß München, 1969, Apimondia-V., Bukarest, 1969.

Gilmour, D. : The Biochemistry of Insects, Academic Press, New York, 1961.

Gilmour, D. : The Metabolism of Insects, Oliver a. Boyd, Edinburgh, 1965.

Glinski, Z., u. T. Kostarz : Med. Wet. (Poland) 24, 183 (1968), ref. : C.A. 69, 25302 w (1968).

Gontanski, H., u. I. HoffmanN : Z. Bienenforsch. 6, 184 (1962-63).

GrAY, R.-A. : Science (Washington) 115, 129 (1952).

de Groot, A.-P. : Protein and amino acid requirements of the honey-bee, Proefschrift, Den Haag, 1953.

HahN, Hj. : Dissertation Stuttgart 1970.

Haseloff, O.-W., u. H.-J. Hoffmann : Kleines Lehrbuch der Statistik, 2. Auflage, de Gruyter, Berlin, 1965. 
Herold, E. : in Biene und Bienenzucht. A. Büdel u. E. Herold (Hrsg.), Ehrenwirth V., München, 1960.

Kalimi, M.-Y., u. K. Sоноnie : J. Nutr. Dietet. (Coimbatore) 1, 261 (1964).

Kirsten, E., R. Kirsten u. P. Arese : Biochem. Z. 337, 167 (1963).

Komamine, A. : Suomen Kemistilehti 33 B, 185 (1960).

Lensky, Y. : Traité de biologie de l'abeille, R. Chauvin (ed.), Bd. 1, Masson et Cie., Paris, 1968 •

Lothrop, R.-E., u. S.-I. Gertuer : Ind. Engng. Chem., analyt. Edit. 5, 103 (1933).

LïtTGE, U. : Planta 56, 189 (1961).

Maltais, I.-B., u. I.-L. Auclair : Canad. J. Zool. 30, 191 (1952).

Maslowski, P., u. I. Mostowska : Pszczel. Zesz. Nauk. 7, 1 (1963) ref. : C. A. 60, 2258 c (1964).

Maurizio, A. : Das Waldhonigbuch. W. KLoft, A. Maurizio, W. Kaeser (Herg). EhrenwirthV., München, 1965.

Michelotti, P., u. G. Margheri : Scienza Alimentazione 15, 179 (1969).

Modi, G., u. R. Brffoli : Boll. Lab. chim. provinc. 18, 25 (1967).

Mostowska, I. : Zesz. Nauk. Wyzsz. Szk. Roln. Olsztynie 20, 417 (1965).

Mostowska, I., u. D. WAnic : Zesz. Nauk. Wyzsz. Szk. Roln. Olsztynie 24, 189 (1968).

OKADA, I. : Bulletin of the Faculty of Agriculture Tamagawa University, Machida-shi, Tokyo, No. 7. 8, 173 (1968).

Pataki, G. : Dünnschichtchromatographie in der Aminosäure-und Peptid-Chemie, de Gruvter. Berlin, 1966.

Prate, J. J., u. H.-L. House : Science (New York) 110, 9 (1949).

REMBOLD, H. : Naturwissenschaften 51, 49 (1964).

Virtanen, A.-I., u. S. Kari : Acta chem. scand. 9, 1548 (1955).

VorwoHL, G. : Z. Bienenforsch. 9, 232 (1968).

White jr., I.-W., u. A.-I. Schepartz : Biochim. biophysica Acta (Amsterdam) 73, 57 (1963).

Zacharius, R.-M., u. W.-L. Porter : J. Chromatog. 30, 190 (1967).

\section{Anmerkung :}

Zur Bezeichnung der Aminosäuren in den Tabellen wurden die von der IUPAC - IUB Kommission für biochemische Nomenklatur (1965) vorgeschlagenen Abkürzungen verwendet.

\section{Anschriften der Verfasser :}

Prof. Dr. K.-G. Bergner u. Dr. Hj. Hahn, Institut für Lebensmittelchemie der Universität Stuttgart, 7 Stuttgart 1, Keplerstr. 17. 